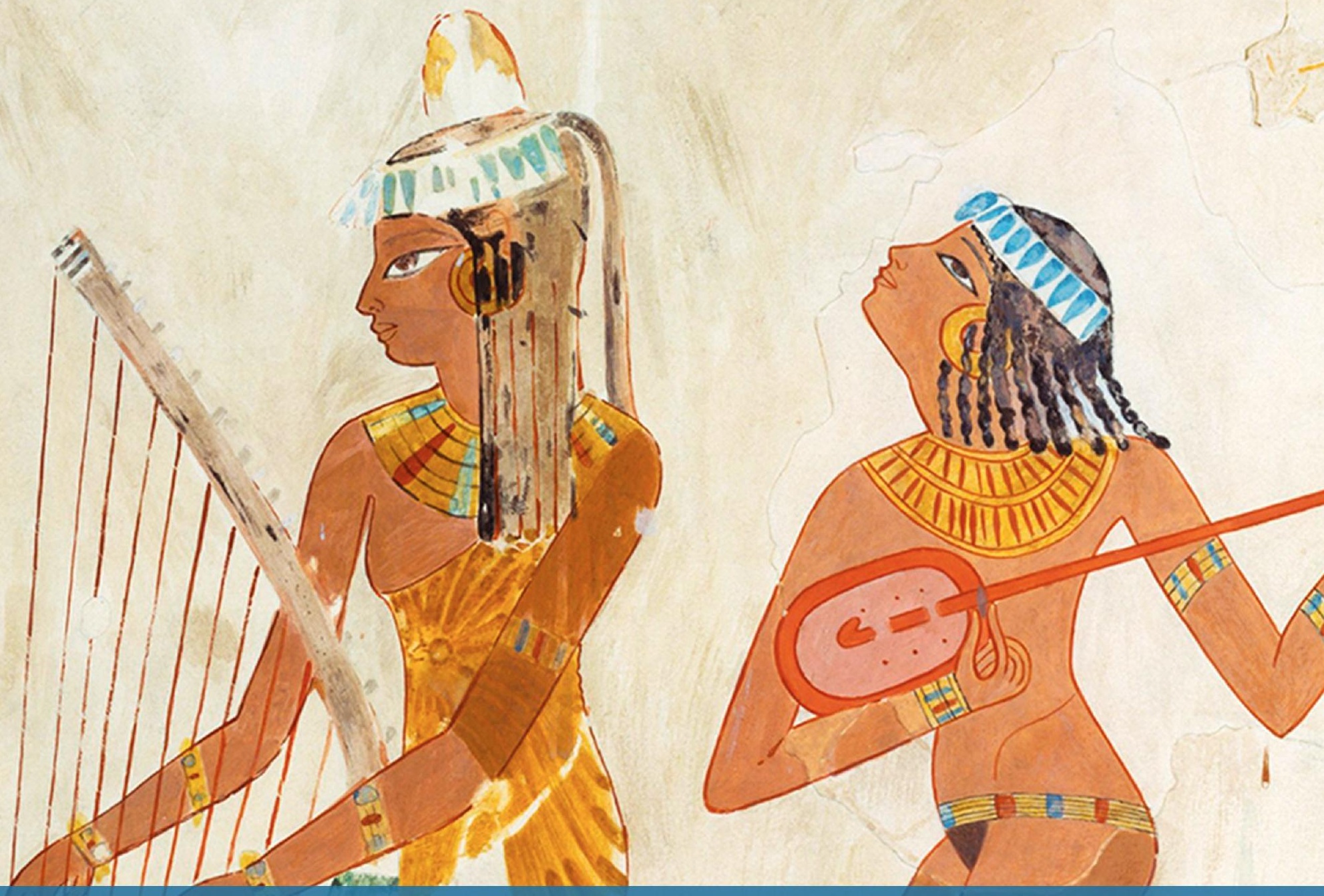

Revista digital de ciencia y Didáctica de la Historia

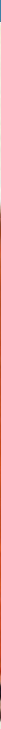




\section{Panta Rei \\ Revista Digital de Ciencia \\ y Didáctica de la Historia}

\section{9}

Revista anual

Fecha de inicio: 1995

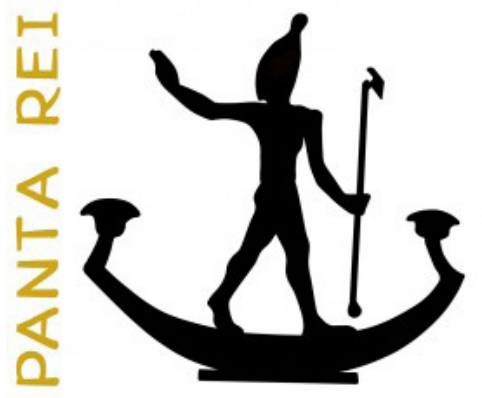

Revista Panta Rei. pantarei@um.es

Edita:

Centro de Estudios del Próximo Oriente y la

Antigüedad Tardía - CEPOAT

Edificio Universitario Saavedra Fajardo.

Universidad de Murcia

C/ Actor Isidoro Máiquez, 9

30007 - MURCIA - ESPAÑA

Teléfono: (+34) 868883890

cepoat@um.es

Web: www.um.es/cepoat/pantarei

Edición 2019

ISSNe: 2386-8864

Responsable de la presente edición: Consejo Editorial Panta Rei.

UNIVERSIDAD DE MURCIA centro de estudios del próximo oriente y la antigüedad tardía

En Portada: Fragmento de pintura de la tumba de Djeserkareseneb (TT38), Tebas. (fotografía del Metropolitan Museum).

Responsables de los textos: Sus autores.

ISSN: 1136-2464

Depósito legal: MU-966-1995 


\section{CONSEJO DE REDACCIÓN}

\section{Coordinador editorial}

Egea Vivancos, Alejandro

[Didáctica de las Ciencias Sociales, UMU]

\section{Editores}

Jiménez Vialás, Helena

[UMU]

López Muñoz, Dámaris

[UJA]

Meseguer Gil, Antonio José

[CEPOAT, UNED]

Sáez Giménez, David Omar

[CEPOAT, UMU]

Sánchez Mondéjar, Celso Miguel

[Patrimonio Inteligente]

\section{Secretaria}

Arias Ferrer, Laura

[Didáctica de las Ciencias Sociales, UMU]

\section{Responsable informático}

Martínez García, José Javier

[CEPOAT, UMU]

\section{Traducción y corrección lingüística}

Martínez Martínez, Cristina

[Sociedad Española de Lenguas Modernas]

Albaladejo Albaladejo, Sara

[ISEN, UMU]

\section{CONSEJO ASESOR}

Adroher Auroux, Andrés María [Arqueología, Universidad de Granada]

Albero Muñoz, M. ${ }^{a}$ del Mar [Historia del Arte, Universidad de Murcia]

Alia Miranda, Francisco [Historia Contemporánea, UCLM]

Arciniega García, Luis [Historia del Arte, Universidad de Valencia]

Barrio Barrio, Juan Antonio [Historia Medieval, Universidad de Alicante]

Castellano i Solé, Núria [Egiptología, Schola Didàctica Activa S.L.]
Chapman, Arthur [History Education, University College of London, Reino Unido]

Cid López, Rosa María [Historia Antigua, Universidad de Oviedo]

Cobacho López, Ángel [Derecho, Universidad de Murcia]

Cuenca López, José María [Didáctica de las Ciencias Sociales, Universidad de Huelva]

Egea Bruno, Pedro M. ${ }^{a}$ [Historia Contemporánea, Universidad de Murcia]

Feijoo Martínez, Santiago [Arqueología, Consorcio Ciudad Monumental de Mérida]

García Atienzar, Gabriel [Prehistoria, Universidad de Alicante]

Ginestí Rosell, Anna [Filología Clásica, Katholische Universität Eichstätt-Ingolstadt]

González Monfort, Neus [Didáctica de las Ciencias Sociales, Universidad Autónoma de Barcelona]

González Soutelo, Silvia [Arqueología, Universidad de Vigo]

Haber Uriarte, María [Prehistoria, Universidad de Murcia]

Hernández de la Fuente, David [Historia Antigua, Universidad Complutense]

Hutson, Scott R. [Anthropology, University of Kentucky, EE UU]

Igual Luis, David [Historia Medieval, UCLM]

Irigoyen López, Antonio [Historia Moderna, Universidad de Murcia]

Jover Maestre, Francisco Javier [Prehistoria, Universidad de Alicante]

Mahony, Simon [Digital Humanities, University College of London, Reino Unido]

Marsilla de Pascual, Francisco Reyes [Técnicas historiográficas, Universidad de Murcia]

Martínez-Burgos García, Palma [Historia del Arte, UCLM]

Mathis, Christian [Didaktik der Geschichte, PH Zürich]

Miralles Maldonado, José Carlos [Filología Clásica, Universidad de Murcia]

Molina Gómez, José Antonio [Historia Antigua, Universidad de Murcia]

Mónica Ghirardi [Historia Moderna, Universidad Nacional de Córdoba, Argentina]

Navarro Espinach, Germán [Historia Medieval, Universidad de Zaragoza]

Noguera Celdrán, José Miguel [Arqueología, Universidad de Murcia]

Ortiz Heras, Manuel [Historia Contemporánea, UCLM]

Panzram, Sabine [Historia Antigua, Universität Hamburg]

Pérez Molina, Miguel Emilio [Filología Clásica, Universidad de Murcia]

Prados Martínez, Fernando [Arqueología, Universidad de Alicante]

Sánchez Ibáñez, Raquel [Didáctica de las Ciencias Sociales, Universidad de Murcia]

Sancho Gómez, Miguel Pablo [Educación, UCAM]

Victoria Moreno, Diego [Historia Contemporánea, UNED]

Vilar García, María José [Historia Contemporánea, Universidad de Murcia]

Vivas Sainz, Inmaculada [Historia del Arte, UNED]

Zamora López, José Ángel [Próximo Oriente Antiguo, CCHS-CSIC] 



\section{Índice}

\section{Artículos}

La imagen de la Prehistoria en el cine y los géneros del cine prehistórico. Un mundo de hombres mono, bikinis y dinosaurios.

Alberto Lombo Montañés.

Trabajo y roles de género durante la Prehistoria. Un estudio sobre su percepción en el alumnado de Historia.

María Pastor Quiles y Daniel Mateo Corredor.

Memoria cultural en el Egipto Faraónico. Algunas reflexiones sobre su origen, función y pervivencia histórica.

Antonio Pérez Largacha.

La representación de la danza dentro de las escenas de banquete de las tumbas tebanas privadas de la XVIII dinastía egipcia.

Miriam Bueno Guardia.

La "Sala del Fresco" de Micenas. Revisión de las interpretaciones del programa iconográfico y nueva lectura en relación a los espacios.

Pelayo Huerta Segovia.

Las advertencias de Quilón y Solón sobre la tiranía de Pisístrato.

Unai Iriarte.

La Virgen de la Leche. Arquetipo de mujer y madre en la pintura del Renacimiento español.

Patricia Castiñeyra Fernández

Innovación didáctica en Historia: un estado de la cuestión en torno a cuatro ejes temáticos.

Diego Luna Delgado.

\section{Reseñas}

Foster, B. R. (2016), The Age of Agade. Inventing empire in ancient Mesopotamia, Londres y Nueva York: Routledge, 438 págs.

Juan Álvarez García.

Alviz Fernández, M. y Hernández de la Fuente, D. (Eds.) (2017). De ópos a limes: el concepto de frontera en el mundo antiguo y su recepción. Madrid: Escolar y Mayo editores. 256 págs.

Ethan Yepes de la Hoz.

Clares Clares, M ${ }^{\mathrm{a}}$ E. (2017). Música y noches de moda. Sociedades, cafés y salones domésticos de Murcia en el siglo XIX. Murcia: Universidad de Murcia, Servicio de Publicaciones. 474 págs.

Elena Micó Terol 195

Goñi Zabalegui, A. (2018). Género y sociedad en el Egipto romano. Una Mirada desde las cartas de mujeres. Oviedo: Ediciones de la Universidad de Oviedo. 360 págs.

Alejandra Izquierdo Perales. 199

Normas de publicación/Publishing rules 



\title{
La representación de la danza dentro de las escenas de banquete de las tumbas tebanas privadas de la XVIII dinastía egipcia
}

\author{
The Representation of Dance Within the Banquet Scenes of the Private Theban
}

Tombs of the Eighteenth Dynasty of Egypt

Bueno Guardia, Miriam ${ }^{1}$
Universidad Nacional de Educación a Distancia (UNED)

Recibido: 30/01/2019

Aceptado: $27 / 05 / 2019$

Para citar este artículo: Bueno Guardia, M. (2019). La representación de la danza dentro de las escenas de banquete de las tumbas tebanas privadas de la XVIII dinastía egipcia. Panta Rei. Revista Digital de Ciencia y Didáctica de la Historia, 69-89.

ISSNe: 2386-8864

DOI: $10.6018 /$ pantarei/2019/04

\section{Resumen}

El presente artículo es fruto de una investigación sobre la representación de la danza en las tumbas tebanas privadas del Reino Nuevo (1550-1070 a.C.). En él se pretende poner en contexto la representación de la danza dentro de las conocidas escenas de banquete de la XVIII dinastía (1550-1295 a.C.), así como analizar, mediante el estudio de todas las escenas encontradas, sus características principales y su simbología. Por último, se intentará explicar su posible interpretación, basada en el contexto en el que aparecen, y las convenciones utilizadas para su representación. Por lo tanto, se resaltarán los elementos comunes de estas escenas (ubicación, iconografía...) que son los que nos ayudan a entender su significado e importancia.

Se trata de un tema relevante, ya que estas escenas de banquete en las que aparecen bailarinas estaban cargadas de contenido simbólico y estético, y servían de nexo entre el difunto y los visitantes de la tumba. Tenían así, por lo tanto, una gran importancia para el pensamiento religioso egipcio, pues ayudaban a la supervivencia del difunto en el Más Allá.

\section{Palabras clave}

Arqueología, Artes visuales, Historia del Arte, Pintura (artes visuales), Música, Historia Antigua.

\section{Abstract}

The present paper is the result of an investigation about the representation of dance within the banquet scenes found in the decoration of the private Theban tombs of the New Kingdom (15501070 B.C.). It aims to put in context the representation of dance within the well-known banquet scenes of the Eighteenth Dynasty (1550-1295 B.C.), as well as analyse, through the study of all the scenes found, its main characteristics and its symbolism. Finally, I will try to explain its possible interpretation, based on the context in which the images appear, and the conventions used for its

1 Para contactar con la autora: Miriam Bueno Guardia. Universidad Nacional de Educación a Distancia (UNED). mbueno162@alumno.uned.es. 
representation. Therefore, the common elements in these scenes (location, iconography...) will be highlighted as they are the key to understand their meaning and importance.

This is a relevant issue, since these banquet scenes in which we can see female dancers were loaded with symbolic and aesthetic content, and would serve as a link between the deceased and the visitors of the tomb. They had, therefore, a great importance for Egyptian religious thought as they helped the survival of the deceased in the Hereafter.

\section{Keywords}

Archaeology, Visual Arts, Art History, Painting (Visual Arts), Music, Ancient History.

\section{Introducción}

Aunque a lo largo del tiempo las escenas de banquete han sido estudiadas de modo puntual por diferentes investigadores, no existe hasta la fecha un compendio de las escenas de danza en ellas encontradas, por lo que, aunque no se incluirán aquí todas las imágenes, se pretende ofrecer en este trabajo una síntesis de sus rasgos y un listado de las mismas, destacando algunas de ellas por sus peculiaridades y agrupando otras por sus similitudes.

Pero, en primer lugar, es necesario ofrecer un contexto en el que situar estas escenas. Por ello se empezará hablando del contexto geográfico, la necrópolis tebana privada, para después hacer un análisis de las características generales de las propias tumbas tebanas privadas en las que son representadas estas escenas de banquete. Ello nos permitirá conocer su simbología y la importancia de la ubicación de las representaciones de danza en banquetes dentro de ellas.

A continuación se hará una breve aproximación a la danza en el Reino Nuevo (1550-1070 a.C.) y un análisis pormenorizado de las propias escenas de banquete para entender su significado oculto y cómo éste está condensado en las propias representaciones de danza. Cabe mencionar, como se explicará más adelante, que la danza en el antiguo Egipto escondía un significado simbólico que nos es interpretable gracias al contexto en el que se sitúan las imágenes.

La última parte de este artículo se centrará en estas escenas de danza, analizando sus principales características e intentando extraer su posible interpretación, así como las convenciones o normas usadas por los antiguos egipcios para este tipo de representaciones.

El compendio de las mismas se ha realizado gracias a la bibliografía topográfica de Porter y Moss (1970) y de otras publicaciones específicas, mencionadas más adelante. A continuación, las escenas encontradas se han clasificado según su localización geográfica y dentro de las propias tumbas. Posteriormente, se han analizado formal y estilísticamente para después proceder a su comparación. También se han intentado analizar simbólicamente los elementos más repetidos en estas escenas para poder descifrar así, a través de ellos, su significado.

\section{El contexto geográfico: la necrópolis tebana privada en el Reino Nuevo}

El contexto geográfico de las escenas objeto de estudio en este artículo es Tebas, que es el nombre griego de la ciudad egipcia de Waset, capital religiosa de Egipto desde inicios del Reino Nuevo. Esta ciudad abarcaba aproximadamente la zona que se encuentra entre los templos de Karnak y Luxor, aunque ocupando ambas orillas del río Nilo. En su parte occidental, en una zona de unos dos kilómetros de largo, se sitúan distintas necrópolis, tanto reales como privadas, usadas a lo largo del Reino Nuevo: el Valle de los Reyes, el Valle de las Reinas, Deir el Medina, Qurnet Murai, Sheik Abd el-Qurna (también conocida como el "valle de los nobles"), Deir el-Bahari, el-Khôkha, Dra Abu el-Naga y el-Asasif. Sin embargo, cabe recordar que la delimitación de la necrópolis tebana no es la misma en tiempos antiguos que en la actualidad, pues entonces se conocía como un espacio sagrado único con el nombre de "El Oeste de Tebas" o 'Imntt $n$ wsst, sin las divisiones que se utilizan hoy en día para facilitar el estudio (Jiménez, 2016).

El uso de esta necrópolis privada tebana, donde se encuentran las escenas de danza en las 
que se centra este artículo, comienza en la VI dinastía en la zona de el-Khôkha y ya en el Reino Nuevo, durante la primera mitad de la XVIII dinastía comienzan a excavarse tumbas en Dra Abu el-Naga, el-Asasif y en la parte más alta de Sheik Abd el-Qurna, extendiéndose la ocupación en la segunda mitad de la dinastía a la parte baja de Sheik Abd el-Qurna, Deir el-Medina, el-Khôkha y Qurnet Murai. Es en esta época cuando se produce un mayor uso de la necrópolis, aunque se seguirá usando en las dinastías posteriores.

Deir el Medina, la zona más meridional, fue el poblado donde habitaban los trabajadores que tallaron y decoraron las grandes tumbas reales de toda la montaña. A su izquierda se concentra la mayor parte de las tumbas de estos trabajadores, que sirvieron para varias generaciones distintas. Las tumbas más antiguas de esta necrópolis, datadas del reinado de Hatshepsut, se encuentran en la parte este, mientras que las de época post-amarniense se encuentran en la parte oeste.

Sheik Abd el-Qurna, sección central de la necrópolis tebana, es una de las más importantes de la zona, con el mayor número de tumbas de la XVIII dinastía (1550-1295 a.C.), pertenecientes a personajes de la administración y la burocracia real. Comenzó a utilizarse a la vez que el Valle de los Reyes con enterramientos consistentes en tumbas-pozo, la mayoría sin capillas (Bryan, 2010). La parte alta de la colina, la primera en ocuparse porque permitía la vista directa del templo de Karnak sobre los templos funerarios reales, se utilizó hasta el reinado de Amenhotep III. Entonces la estructura de las tumbas se volvió más compleja, haciéndose frecuente el uso de salas hipóstilas, para lo que era necesario más espacio y una roca de mejor calidad, pasando así a ocuparse el nivel inferior de la colina, además de por la gran densidad de ocupación de la parte alta y la parte central (Seidel, 1996; Smith, 2009).

La necrópolis de Dra Abu el-Naga, al norte, es amplia tanto por su extensión (con aproximadamente un kilómetro de largo y 250 metros de ancho) como por su cronología, encontrando en ella tumbas de las dinastías XVII y XVIII. Aunque esta zona se asociara durante siglos a la familia real de Ahmose, una vez que las tumbas reales dejaron de excavarse aquí, el pie de la colina perduró como la parte más elitista de la necrópolis durante unas pocas décadas (Bryan, 2010).

En la zona de el-Khôkha se hallan tumbas datadas desde el Reino Antiguo hasta la Baja Época o Periodo Tardío. Por último, en el-Asasif se encuentran la mayor parte de las tumbas relevantes de la Baja Época, aunque, como ya se ha dicho, en la zona también se pueden encontrar tumbas de la XVIII dinastía.

\section{El contexto de las escenas: las tumbas tebanas privadas}

Para comprender la importancia de las escenas de banquete y su simbolismo es necesario analizar el contexto funerario en el que se atestiguan.

En primer lugar, cabe aclarar que cuando hablamos de "tumbas tebanas privadas" nos referimos comúnmente a las tumbas de altos funcionarios, personajes que formaban una elite entre la población. Éstas normalmente se encuentran agrupadas cerca de residencias reales o de las capitales de provincia (Vandier, 1964), en este caso, como ya se ha mencionado, en las necrópolis de la que fue capital religiosa egipcia durante gran parte de la XVIII dinastía.

En cuanto a su función, la tumba protegía el cuerpo del difunto, aseguraba su transformación y su bienestar eterno, servía como monumento para proyectar la identidad del propietario en la otra vida y le conmemoraba en el mundo de los vivos (Hartwig, 2004). Así, tener una tumba era algo fundamental para los egipcios, cuyas creencias estaban basadas en la existencia de un Más Allá y por lo tanto necesitaban un lugar para conservar el cuerpo del difunto y posibilitar su tránsito. Esta función queda bien reflejada en el propio nombre que se les daba a las tumbas: casa de la eternidad ( hwt $n$ nhh $q$ pr $\underline{d} t$ ) (Vivas, 2014).

La estructura de estas tumbas privadas (Figura 1), que están excavadas en la montaña, solía basarse en un patio, seguido de una sala (en ocasiones a modo de sala transversal), que daba paso a un corredor o sala alargada por la que se accedía a una pequeña cámara funeraria o capilla. Este modelo es el conocido como "tumba con planta de T invertida", muy habitual en la XVIII dinastía 
(1550-1295 a.C.). Además, existen tumbas con distintas cámaras anexas a estas salas principales. Se denominan tumbas-capilla, pues son lugares tanto de enterramiento como de culto funerario.

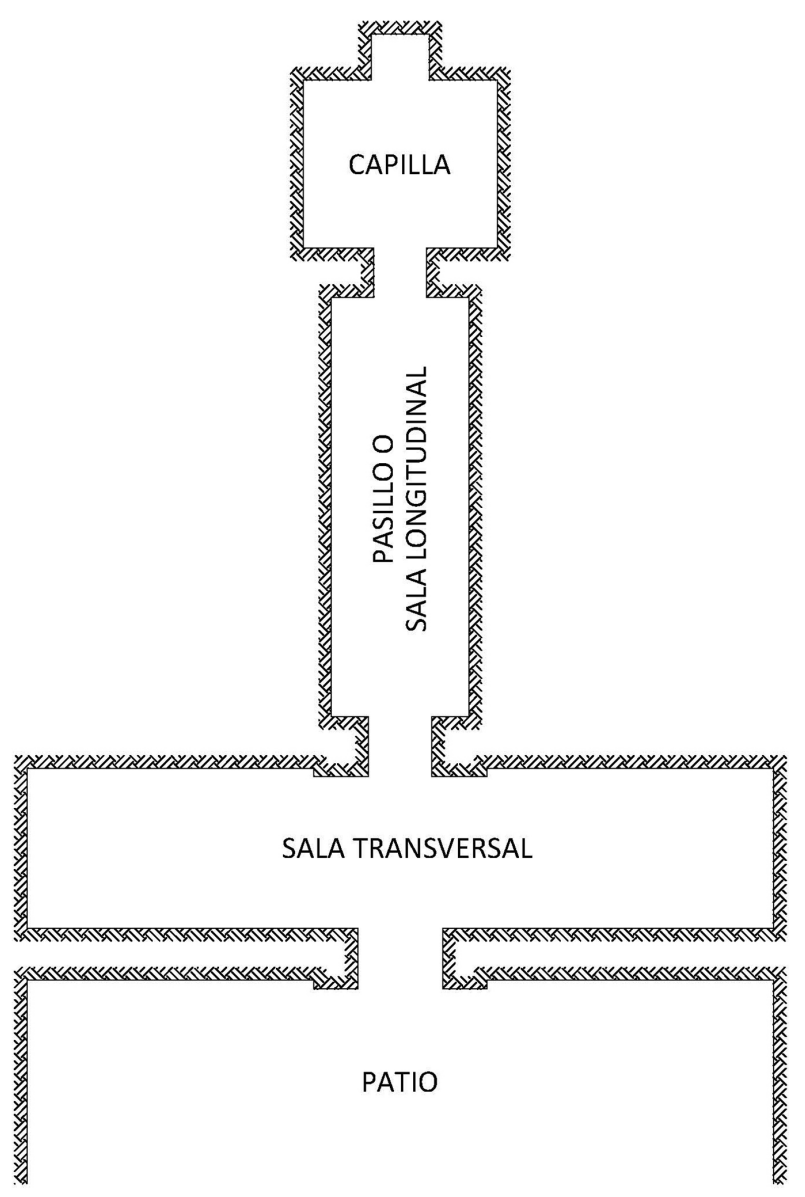

Figura 1: Plano de la estructura típica de una tumba tebana privada de la XVIII dinastía. Fuente: elaboración propia.

Siguiendo la clasificación de Kampp-Seyfried (2003) (Figura 2) de las tumbas tebanas en cuanto a su forma, la típica forma ya mencionada (tipo $\mathrm{V}$ ) evoluciona desde otro modelo típico del Reino Medio (tipo III), pasando por una etapa intermedia (tipo IV), en la que poco a poco el antiguo pórtico se va convirtiendo en una sala transversal, conteniendo además una decoración con una temática similar en todas las tumbas, las llamadas "escenas de la vida cotidiana" (entre las que se encontrarían las escenas de banquete), aunque ésta puede ser bastante variada en función, por ejemplo, de la profesión del propietario.

Por otra parte, las tumbas se estructuraban en tres niveles distintos: uno superior con una estructura que incluía un patio y una fachada y que correspondía principalmente con funciones relacionadas con el culto solar; uno intermedio que se corresponde con las capillas, donde se celebraba el culto al difunto y donde se reunían familiares y amigos con motivo de los distintos festivales (como el de Año Nuevo y la "Bella Fiesta del Valle", de la que se hablará más adelante), y que ya es subterráneo; y uno más interno que se corresponde con las cámaras de enterramiento y que se relaciona con el dominio de Osiris, con el inframundo. 


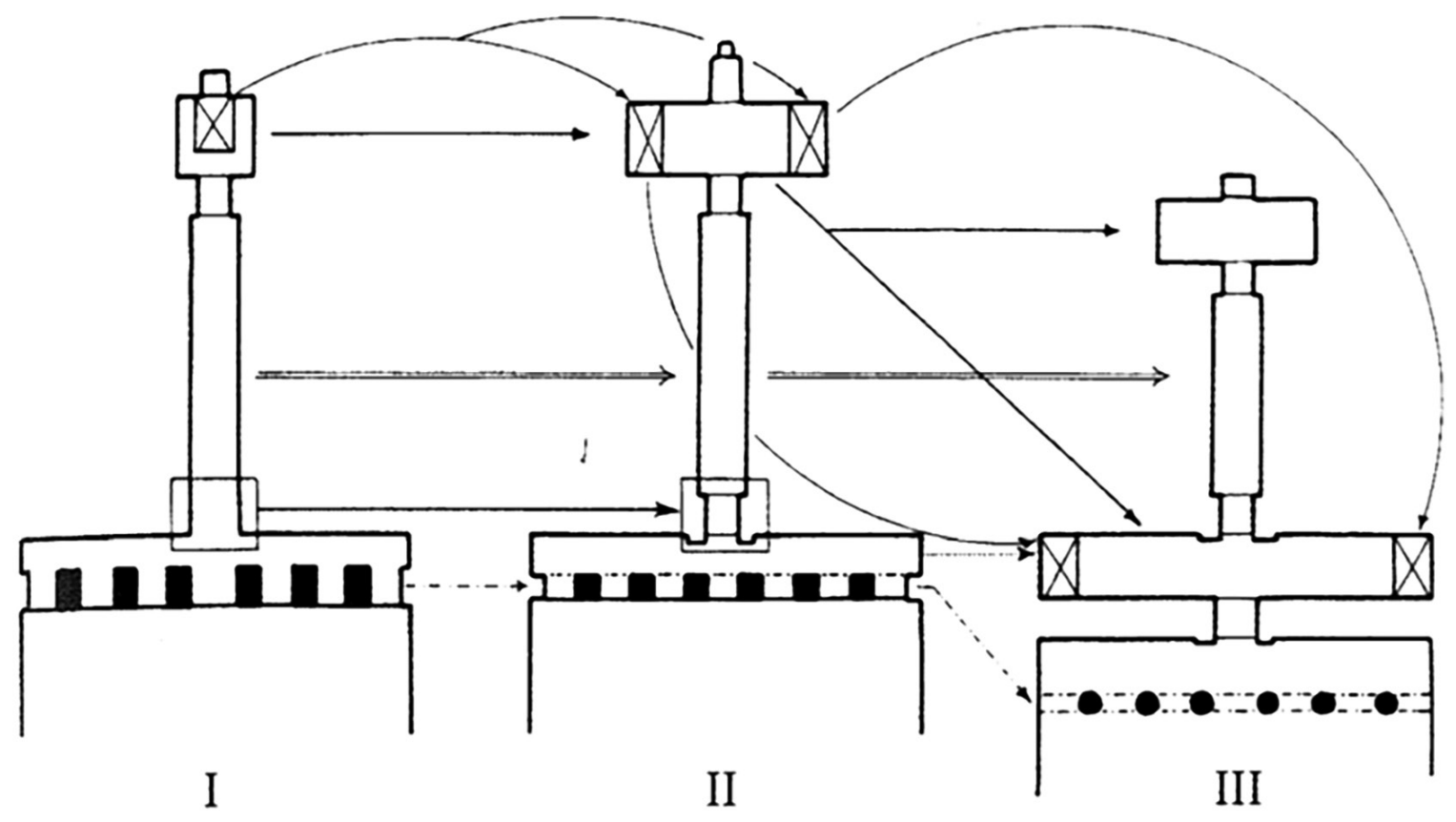

Figura 2: Evolución de la estructura de las tumbas tebanas privadas. Fuente: Kampp-Seyfried, 2003, fig. 5.

Su orientación ideal durante la XVIII dinastía sería hacia el oeste, y el programa decorativo se organizaba en este eje como un reflejo metafórico de la transición de la vida (este) a la muerte (oeste). Así, las escenas de la sala más "oriental", la sala transversal de las tumbas en forma de T invertida, estaban relacionadas con la vida del difunto y las de la sala interior, más "occidental", se relacionaban con su transición y vida en el Más Allá (Hartwig, 2004).

Por otra parte, la construcción de una tumba es un elemento de distinción social, estando además muy relacionados en el antiguo Egipto lo social y lo funerario (Dodson e lkram, 2008). Así, el tamaño, la calidad y la originalidad de la decoración de las tumbas están vinculados a la importancia del propietario, que probablemente tenía cierta influencia a la hora de elegir sus características y decoración, lo que simbolizaba su biografía y la suma de sus logros.

Pero estos espacios estaban pensados no sólo como monumentos conmemorativos para los propietarios de las tumbas y sus familias, sino también como espacios donde realizar rituales de enterramiento y ceremonias (Vivas Sainz, 2014).

Así, la supervivencia del difunto y su transición al Más Allá dependía de la eficacia del culto funerario y los rituales, por lo que cobra gran importancia la interacción entre los vivos y los muertos dentro de las tumbas en las ocasiones en las que estos lugares eran accesibles. Familiares, sacerdotes e incluso visitantes al azar realizaban actividades de culto, dejaban ofrendas o pronunciaban oraciones por el propietario de la tumba en su interior, cumpliendo así parte de la que era su función (Hartwig, 2004). Pero estas tumbas no sólo eran visitadas tras la muerte del propietario, sino que el culto en la tumba comenzaba una vez terminada su construcción o su decoración, lo que podía ocurrir tiempo antes de la defunción (Bolshakov, 1991).

Estas visitas, atestiguadas por la presencia de distintos graffiti, explican la importancia de la decoración de las primeras salas ya mencionadas, ya que la sala más profunda se encontraba sellada (Navrátilová, 2010). Así, la sala transversal se convirtió en el "espacio público" de la tumba, donde el propietario probablemente ubicaría las escenas que considerase más importantes (Vivas Sainz, 2014). Dentro de la propia sala transversal, destaca la importancia de las llamadas "paredes 
focales" ("Blickpunktsbild"), que son las primeras que se ven al entrar en la tumba y que recibirían una mayor iluminación natural (Hartwig, 2004). En ellas, el artista egipcio situaría escenas de una estética llamativa o con un significado importante, y que además nos ofrecen información sobre la identidad social del difunto.

Por otra parte, el arte que decoraba estas tumbas no sólo servía para el placer estético, sino que tenía una finalidad determinada: crear un Más Allá ideal para que el difunto viviera allí eternamente. Así, las escenas tenían una función mágica y práctica (Dodson e Ikram, 2008).

En cuanto a la distribución de las escenas que decoran estas tumbas no existe una regla clara, pero sí determinadas tendencias: normalmente, las escenas biográficas, profesionales, de banquete $o$ de ofrendas se encuentran en la sala transversal, mientras que las escenas funerarias se encuentran en el pasillo o en la segunda sala, la más interior, que también puede encontrarse desprovista de decoración. Así, el programa iconográfico se centra en motivos funerarios y en las llamadas "escenas de la vida cotidiana", que en realidad tenían un doble sentido y formaban parte también de las creencias funerarias de los egipcios (Manniche, 1997 y Smith, 2009). Se trata de un deseo de cruzar los límites entre ambos mundos, el de los vivos y el de los muertos, para que el difunto pudiera estar en contacto de nuevo con los que había dejado atrás (Manniche, 2003).

Durante la XVIII dinastía (1550-1295 a.C.), los detalles de la vida terrenal y los acontecimientos importantes vividos por el propietario de la tumba, en definitiva, las "escenas de la vida cotidiana", se vuelven más comunes en los relieves y pinturas funerarios. Pretenden dejar un testimonio de la vida del difunto que pudiera ser recordado por los visitantes que accedían a la capilla durante años y tener la función mágica de revivir perpetuamente lo mejor de su existencia en la Tierra (Aldred, 1951). Posteriormente aumentará la importancia de los motivos religiosos.

Por otra parte, cabe destacar que en el programa decorativo de las tumbas influyen dos preocupaciones distintas: por un lado, se encuentra la elección del propietario a la hora de planificar su monumento, existiendo evidencias de su influencia a la hora de seleccionar y encargar determinadas escenas representativas de su condición social; por otro, encontramos a los artesanos, especializados en ciertos motivos iconográficos. En cualquier caso, ambos grupos se basarían en la existencia de determinados modelos (Den Doncker, 2017).

En relación con esto, sabemos que los propietarios de las tumbas o los artistas que las decoraban se inspiraban en otras y las imitaban, pero también estas "copias" o escenas similares pudieron estar basadas en los mencionados manuales o libros de modelos (Manniche, 1997). A pesar de ello, no existen dos tumbas idénticas, sino que cada artista cambiaba pequeños detalles y muchas veces innovaba con nuevas formas de representar los temas habituales del repertorio decorativo (Vivas Sainz, 2014).

\section{Las escenas de banquete de la XVIII dinastía (1550-1295 a.C.)}

Las escenas de banquete son una de las escenas más repetidas en las tumbas tebanas privadas del Reino Nuevo egipcio, sobre todo en la XVIII dinastía, época en la que probablemente formaba parte de la decoración fundamental de todas ellas (Manniche, 1997b). Harrington (2014) señala que es una de las escenas más conocidas debido su imaginería única y que además suele situarse en la sala transversal de las tumbas tebanas con forma de T invertida y en las salas longitudinales de las tumbas de Elkab (en las que, como se mencionará más adelante, también se ha encontrado una representación de danza dentro de una escena de banquete). Sin embargo, este tipo de escenas no se encuentra en las tumbas amarnienses (Padgham, 2012).

Se considera una escena típica dentro de las conocidas como "escenas de la vida cotidiana", que, aunque tengan un significado más allá de una simple escena cotidiana, nos ofrecen información sobre determinados aspectos de la vida en el antiguo Egipto. Este tipo de escenas parecen representar hechos o acciones de la vida diaria de los propietarios de las tumbas (escenas de banquete, de caza y pesca, escenas relacionadas con la agricultura...) pero en realidad todas ellas esconden un simbolismo que nos remite a la idea de renacimiento del difunto en la otra vida. 
En cuanto a las propias escenas de banquete, que tienen su origen en el Reino Medio (20501750 a.C.), éstas nos muestran a personajes en circunstancias ideales, vestidos lujosamente, disfrutando, en un estado de juventud perpetua... Así, es notable que en estas escenas no encontremos ni ancianos, ni enfermos, ni niños, aunque en ocasiones sí aparecen niñas dedicadas a algunas tareas dentro de estas escenas, como bailarinas o sirvientes. Es esta representación ideal el motivo por el que podemos llegar a la conclusión de que estas escenas no son escenas reales o cotidianas, sino que tienen un significado oculto.

Probablemente muchas de ellas estén relacionadas con la conocida como "Bella Fiesta del Valle" (hb nfr $n$ int) (Manzi y Pereyra, 2014), que, desde el Reino Medio y hasta finales del periodo ptolemaico, se celebraba en verano y que probablemente fuera la celebración más importante realizada en la necrópolis tebana (Foucart, 1924; Naguib, 1991; Schott, 1953; Teeter, 2011). De hecho, es posible que incluso el difunto, antes de morir, hubiera celebrado esta festividad en la entrada de su tumba.

Era originariamente una fiesta relacionada con la diosa Hathor que después se vinculó con el culto a Amón-Ra, el dios tebano y nacional del Reino Nuevo. La Fiesta duraba dos días y comenzaba con sacrificios religiosos y continuaba con una procesión que salía de Karnak e iba por la orilla oeste del Nilo con la estatua de Amón, que visitaba los principales templos funerarios reales, Deir el-Bahari y las necrópolis privadas. Ésta era encabezada por el faraón, quien iba acompañado por algunos familiares y sacerdotes y sacerdotisas de la diosa Hathor, así como por instrumentistas y otros personajes. Se trataba de un acontecimiento muy ruidoso, lleno de música que pretendía "despertar" a los difuntos para que se unieran al dios y a sus familiares (Teeter, 2011). Los "peregrinos" llevaban consigo ofrendas florales para el dios y comida que era compartida entre los vivos y los muertos en la propia tumba. Durante la noche, la estatua de Amón descansaba en la capilla de Hathor del templo de Hatshepsut en Deir el-Bahari, en compañía de esta diosa, con quien se unía como símbolo de rejuvenecimiento, renovación y renacimiento. El viaje simbolizaba el ciclo del sol, entrando así tanto los muertos como los vivos en contacto con el dios Amón y borrando los límites entre ambos mundos.

Otras interpretaciones defienden que esta representación era el intento de que el difunto disfrutara en el Más Allá de los banquetes que celebraba mientras vivía. Según Vandier (1964), se trata en su mayoría de ceremonias funerarias o religiosas, festivales de Año Nuevo, y, sobre todo, de la visita anual de Amón a la necrópolis tebana, la ya mencionada "Bella Fiesta del Valle".

Según Harrington (2014), hay dos tipos de escenas de banquete representadas en las tumbas de la XVIII dinastía: los festivales funerarios, relativos al enterramiento, y los mortuorios, que son aquellos en los que participa el difunto.

El llamado banquete fúnebre o funerario crea una nueva etapa en la relación entre el difunto y sus allegados, estableciendo la tradición de celebrar en presencia del propietario de la tumba, y los principios de dependencia y reciprocidad en los cuales los vivos tienen mayor control. Este tipo de banquetes probablemente fueran celebrados justo después del enterramiento del difunto en el propio patio de la tumba. En este tipo de escenas no se encuentran orquestas o sirvientes y además los participantes tienen posturas más estáticas y rígidas (Harrington, 2012).

Por otro lado, las principales características de las escenas de banquetes mortuorios son la presencia de músicos, bailarinas y sirvientes, así como collares florales, lirios, aceites y ungüentos y bebidas alcohólicas. Muchos de estos elementos se relacionan con la diosa Hathor, asociada a los banquetes mortuorios desde al menos el Reino Medio.

Por otra parte, las escenas de banquete representadas en las tumbas sirvieron para conmemorar a varias generaciones de parientes representando a los vivos y muertos en un solo banquete compartido (Bryan, 2009).

Estos banquetes (Figura 3) estaban generalmente presididos por el difunto y su mujer, que eran representados en actitud sedente de un mayor tamaño recibiendo a sus invitados y delante de los cuales se encontraba la mesa con las ofrendas o los alimentos. Constan, además, de distintas etapas que van desde la preparación misma del banquete hasta la presentación de ofrendas a 
los anfitriones. La parte más amplia de la escena la ocupan normalmente los invitados, siempre separados por su sexo y representados en actitudes diversas. Entre ellos se encuentran personas del servicio que les atienden y que en muchos casos se encuentran sirviendo vino y cerveza, siendo este acto un juego de palabras, pues la palabra usada para "verter" tiene, en el lenguaje egipcio, las mismas letras que la palabra que describe el acto sexual (Manniche, 1987). El último grupo a destacar en estas escenas es el formado por las orquestas, acompañado en múltiples ocasiones de bailarinas.

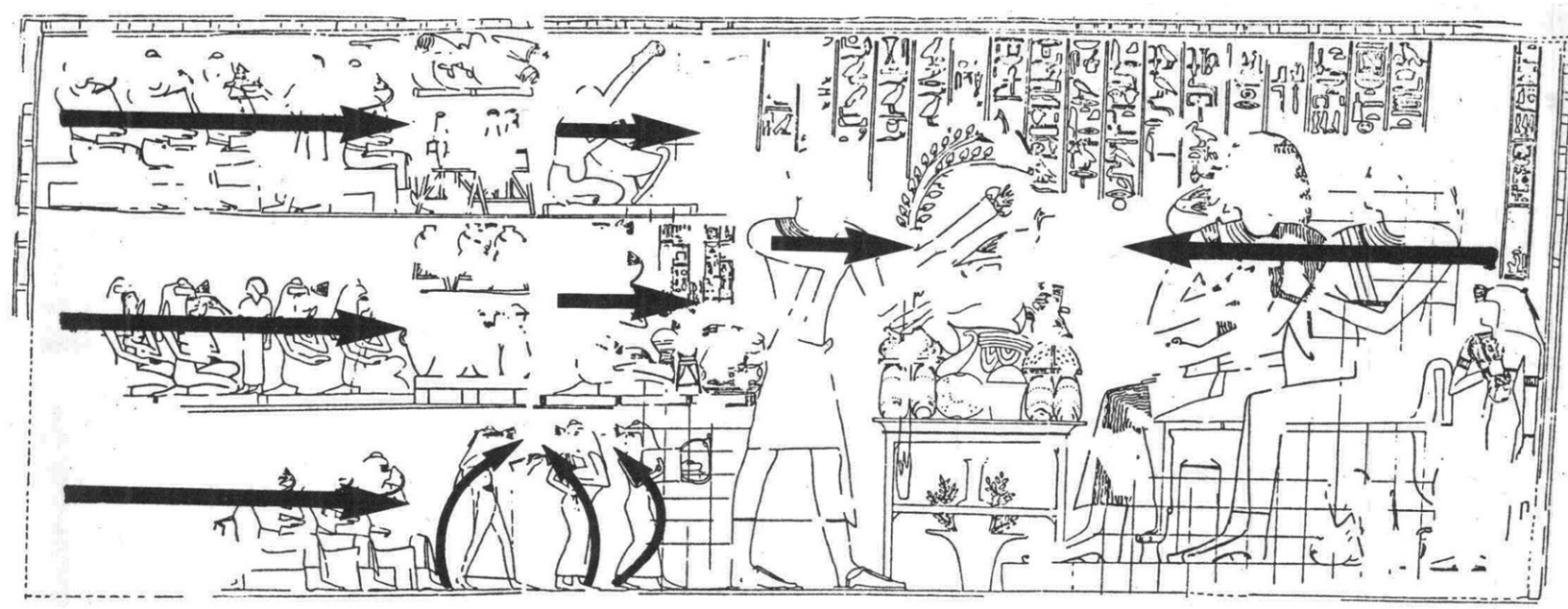

Figura 3: Escena de banquete de la TT80. Fuente: Shedid, 1988, fig. 76.

Algo que llama la atención en estas escenas es que, aunque en ellas aparecen alimentos, no encontramos a gente comiendo, sino que los invitados están únicamente bebiendo vino o cerveza. Así, entendemos que el propósito de estos banquetes era la "intoxicación" para llegar a traspasar los bordes entre el mundo de los muertos y el de los vivos, lo cual, además de con bebidas alcohólicas, se potenciaba con la adición a éstas de distintas plantas (como mandrágora, con efectos afrodisiacos, o persea) (Bosse-Griffiths, 1983) y con el efecto de la música (Manniche, 2003; Szpakowska, 2003). Ésta tendría un efecto relajante y serviría para facilitar la comunicación de los asistentes con las divinidades o con quienes habitaban en el Más Allá. Los músicos y cantores, a través del poder que tenía la palabra hablada o pronunciada, enfatizada además por la música, hacían que la situación se hiciera realidad (Manniche, 1997b).

En algunas inscripciones se menciona que este acto de beber tenía la finalidad de disfrutar de un "día feliz" ( $h r w$ nfr), expresión que se cree que también podía tener ciertas connotaciones sexuales, ya que el término $n f r$ implica dinamismo, potencia, virilidad y eficiencia, cualidades necesarias para el buscado milagro del renacimiento (Manniche, 1997b; 2003). Pero esta expresión también tiene connotaciones sagradas, pudiendo relacionarse con la presencia de lo divino, del dios Amón (Padgham, 2012).

Por otra parte, cabe mencionar que estos banquetes en los que los personajes aparecen bebiendo y no comiendo eran representaciones frecuentes no sólo en Egipto sino también en otros territorios de Oriente Próximo y el Mediterráneo (Harrington, 2012; Morgan, 2015).

Por otra parte, dos elementos muy comunes en estas escenas que nos pueden ayudar a descifrar su significado son la flor de loto y los conos de ungüento, pero, por ser ambos parte del tocado de las bailarinas objeto de este estudio, se analizarán más adelante.

Las vestimentas transparentes, los perfumes y las joyas de las damas que participan en el banquete enfatizan la atmósfera de erotismo. Por su parte, los cabellos están vinculados a la sexualidad en todas las civilizaciones, hecho que se subraya en Egipto con la frecuente presencia de pelucas. 
El objetivo último de todas estas alusiones de carácter sexual era crear un clima propicio para el acto esencial de las creencias funerarias egipcias: el re-nacimiento, el acceso a la vida después de la muerte (Manniche, 1997).

La relación de estos banquetes con Hathor es también notable. Esta diosa, cuyo nombre egipcio significaba "casa de Horus", era la patrona de la necrópolis tebana, protectora materna de los difuntos, la diosa del amor, de la música, de la fertilidad y del nacimiento, así como la "señora de la embriaguez", un estado muy relacionado con su culto (Daumas, 1977; Graves-Brown, 2010; Vischak, 2001). Pero también están relacionados con otros dioses, como Amón, debido a su papel en la "Bella Fiesta del Valle", u Osiris, ya que éste es el dios del inframundo y algunos de estos banquetes tendrían lugar tras la finalización del funeral.

Cabe mencionar, por otra parte, que también se ha encontrado una escena de banquete similar a las descritas y con una escena de danza relacionada con las que son objeto de análisis en este artículo en la tumba de Paheri en Elkab, datada del reinado de Tutmosis III. Es posible que ello se deba a una transferencia de motivos iconográficos entre Tebas y Elkab, ya que Paheri antes de ser nomarca de Elkab fue pintor en Tebas (Laboury, 2017).

\section{La representación de la danza dentro de las escenas de banquete}

Para el estudio de la danza en el antiguo Egipto (Brunner-Traut, 1958; Lexová, 1935; Bleiberg, 2005) debemos usar como fuente primaria las escenas talladas y pintadas en las paredes, en este caso, de las tumbas. Pero su interpretación no es fácil, ya que las imágenes funcionan como una especie de movimiento congelado representativo de la actuación completa y reconocible para aquellos familiarizados con ella (Meyer-Dietrich, 2009).

En el caso de la danza ejecutada en los banquetes, la postura representativa es la de, al menos, un talón levantado y las piernas separadas y flexionadas, que busca transmitir al espectador una sensación movimiento y dinamismo (Figura 4).

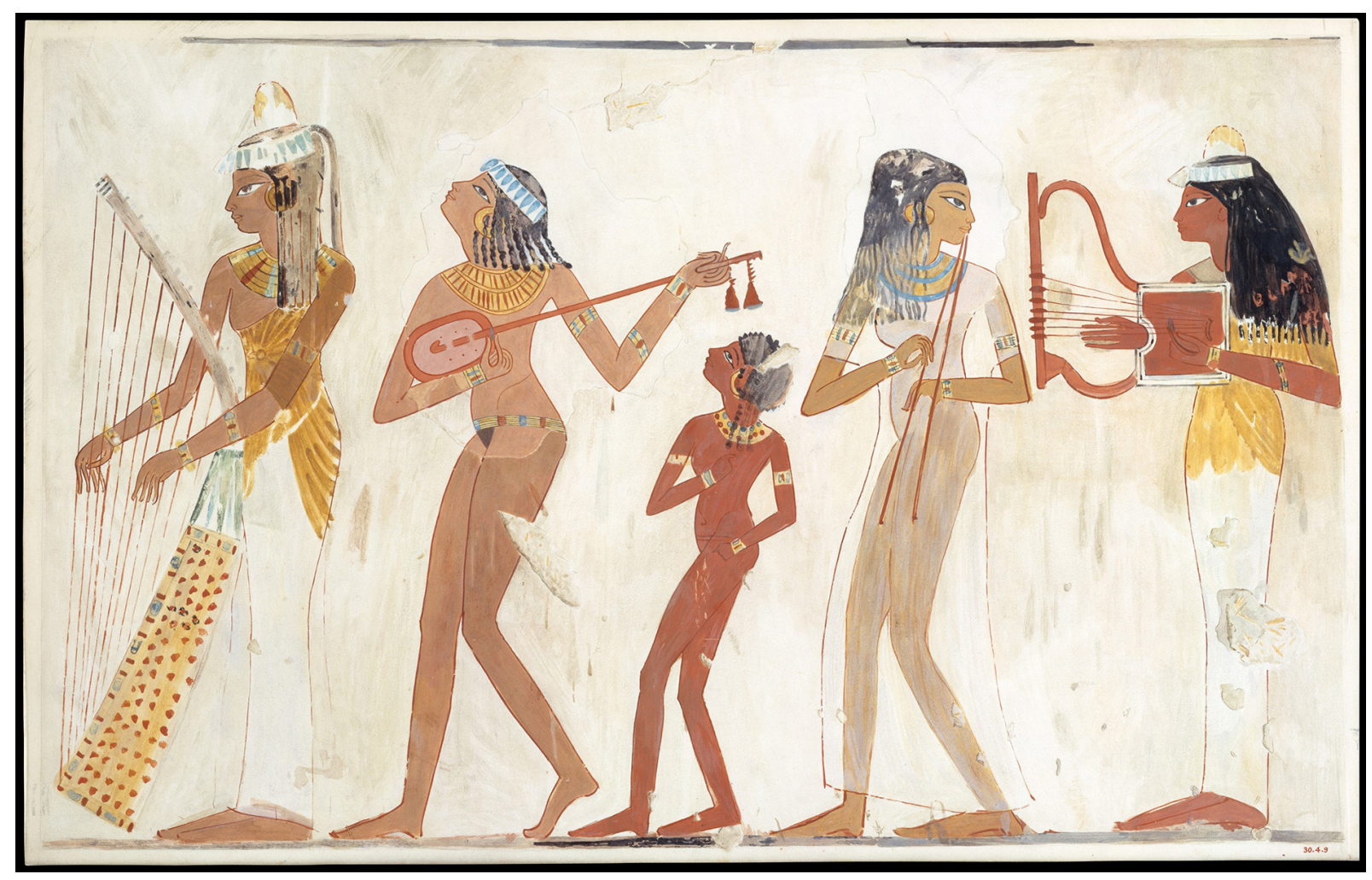

Figura 4: Orquesta femenina de la escena de banquete de la TT38. Fuente: Metropolitan Museum. 
Este tipo de danza se diferencia claramente de otros tipos representados en tumbas y templos del Reino Nuevo, tanto por las participantes como por la forma o postura en la que son representadas, así como por su vestimenta. Dentro de los tipos de danza representados en este periodo podemos encontrar, además de representaciones de danza femenina dentro de banquetes, a bailarines $m w w$ que acompañan a las procesiones funerarias en la decoración de las tumbas privadas y que tienen un tocado o postura característicos, otros ejemplos de bailarinas dentro de orquestas que, por la falta del contexto, no se pueden relacionar con banquetes como los aquí analizados, aunque en ocasiones su postura o la composición de la representación son similares, danzas acrobáticas realizadas también por mujeres y otros grupos minoritarios de los que se han encontrado escasas representaciones, como danzas religiosas, animales o extranjeras (Brunner-Traut, 1958).

Así, podemos ver que en el antiguo Egipto la danza era una actividad realizada en reuniones como banquetes, festividades o funerales que trataba de transmitir un mensaje, que tenía un significado simbólico además de ser una actividad física. Ese mensaje sólo es interpretable si analizamos, como se ha hecho en este artículo, el contexto en el que aparecen estas imágenes.

En total se han documentado 32 ejemplos claros de danza dentro de escenas de banquete en las tumbas tebanas privadas de la XVIII dinastía, incluyendo fragmentos conservados en el Museo Egipcio de Turín, en el British Museum y en la colección Bankes y una copia de una escena realizada por Duemichen (1869) (Tabla 1).

Tabla 1

Representaciones de danza encontradas dentro de escenas de banquete en las tumbas tebanas de la XVIII dinastía

\begin{tabular}{|c|c|c|c|c|}
\hline TT & Lugar & Época & Ubicación & Bibliografía específica \\
\hline 251 & $\begin{array}{l}\text { Sheik Abd } \\
\text { el-Qurna }\end{array}$ & $\begin{array}{c}\text { Hatshepsut - Tutmosis } \\
\text { III }\end{array}$ & $\begin{array}{l}\text { Sala transversal, } \\
\text { pared focal }\end{array}$ & - \\
\hline 53 & $\begin{array}{l}\text { Sheik Abd } \\
\text { el-Qurna }\end{array}$ & $\begin{array}{c}\text { Hatshepsut - Tutmosis } \\
\text { III }\end{array}$ & Sala transversal & - \\
\hline 18 & $\begin{array}{l}\text { Dra Abu } \\
\text { el-Naga }\end{array}$ & Tutmosis III o anterior & Sala transversal & Gauthier (1908) \\
\hline 82 & $\begin{array}{l}\text { Sheik Abd } \\
\text { el-Qurna }\end{array}$ & Tutmosis III & $\begin{array}{l}\text { Sala transversal, } \\
\text { pared focal }\end{array}$ & $\begin{array}{c}\text { Davies y Gardiner (1915) y Den } \\
\text { Doncker (2017) }\end{array}$ \\
\hline 342 & $\begin{array}{l}\text { Sheik Abd } \\
\text { el-Qurna }\end{array}$ & Tutmosis III & Sala transversal & - \\
\hline 79 & $\begin{array}{l}\text { Sheik Abd } \\
\text { el-Qurna }\end{array}$ & $\begin{array}{l}\text { Tutmosis III - } \\
\text { Amenhotep II ? }\end{array}$ & $\begin{array}{l}\text { Sala transversal, } \\
\text { pared focal }\end{array}$ & Virey (1891) y Guksch (1995) \\
\hline 80 & $\begin{array}{l}\text { Sheik Abd } \\
\text { el-Qurna }\end{array}$ & $\begin{array}{l}\text { Tutmosis III - } \\
\text { Amenhotep II }\end{array}$ & $\begin{array}{l}\text { Sala transversal, } \\
\text { pared focal }\end{array}$ & Shedid (1988) \\
\hline 92 & $\begin{array}{l}\text { Sheik Abd } \\
\text { el-Qurna }\end{array}$ & $\begin{array}{l}\text { Tutmosis III - } \\
\text { Amenhotep II }\end{array}$ & Sala longitudinal & Bryan (2001 y 2009) \\
\hline 100 & $\begin{array}{l}\text { Sheik Abd } \\
\text { el-Qurna }\end{array}$ & $\begin{array}{l}\text { Tutmosis III - } \\
\text { Amenhotep II }\end{array}$ & Sala longitudinal & $\begin{array}{c}\text { Davies (1935 y 1943) y Virey } \\
(1889)\end{array}$ \\
\hline 129 & $\begin{array}{l}\text { Sheik Abd } \\
\text { el-Qurna }\end{array}$ & $\begin{array}{l}\text { Tutmosis III - } \\
\text { Amenhotep II }\end{array}$ & $\begin{array}{l}\text { Sala transversal, } \\
\text { pared focal }\end{array}$ & Schenkel (1975) \\
\hline A5 & $\begin{array}{l}\text { Dra Abu } \\
\text { el-Naga }\end{array}$ & $\begin{array}{l}\text { Tutmosis III - } \\
\text { Amenhotep II }\end{array}$ & $\begin{array}{l}\text { Sala transversal, } \\
\text { pared focal }\end{array}$ & Manniche (1988) \\
\hline 22 & $\begin{array}{l}\text { Sheik Abd } \\
\text { el-Qurna }\end{array}$ & $\begin{array}{l}\text { Tutmosis III - } \\
\text { Amenhotep III }\end{array}$ & $\begin{array}{l}\text { Dos escenas. } \\
\text { Sala transversal }\end{array}$ & - \\
\hline
\end{tabular}




\begin{tabular}{|c|c|c|c|c|}
\hline 367 & $\begin{array}{l}\text { Sheik Abd } \\
\text { el-Qurna }\end{array}$ & Amenhotep II & Sala transversal & Fakhry (1943) \\
\hline 75 & $\begin{array}{l}\text { Sheik Abd } \\
\text { el-Qurna }\end{array}$ & $\begin{array}{l}\text { Amenhotep II - } \\
\text { Tutmosis IV }\end{array}$ & Sala transversal & Davies (1923) \\
\hline 176 & El-Khôkha & $\begin{array}{l}\text { Amenhotep II - } \\
\text { Tutmosis IV }\end{array}$ & Sala transversal & Calcoen (2012) \\
\hline 8 & $\begin{array}{l}\text { Deir el- } \\
\text { Medina }\end{array}$ & $\begin{array}{l}\text { Amenhotep II - } \\
\text { Amenhotep III }\end{array}$ & Capilla & $\begin{array}{c}\text { Schiaparelli (2007) y Vandier } \\
\text { d'Abbadie (1939) }\end{array}$ \\
\hline 78 & $\begin{array}{l}\text { Sheik Abd } \\
\text { el-Qurna }\end{array}$ & $\begin{array}{l}\text { Amenhotep II - } \\
\text { Amenhotep III }\end{array}$ & $\begin{array}{l}\text { Dos escenas. } \\
\text { Sala transversal }\end{array}$ & $\begin{array}{c}\text { Bouriant (1889), Brack y Brack } \\
\text { (1980) y Mekhitarian (1957) }\end{array}$ \\
\hline 297 & El-Asasif & $\begin{array}{l}\text { Tutmosis IV - } \\
\text { Amenhotep III }\end{array}$ & $\begin{array}{l}\text { Sala transversal, } \\
\text { pared focal }\end{array}$ & Strudwick (2003) \\
\hline 38 & $\begin{array}{l}\text { Sheik Abd } \\
\text { el-Qurna }\end{array}$ & $\begin{array}{l}\text { Tutmosis IV - } \\
\text { Amenhotep III }\end{array}$ & $\begin{array}{l}\text { Sala transversal, } \\
\text { pared focal }\end{array}$ & Davies (1963) \\
\hline 52 & $\begin{array}{l}\text { Sheik Abd } \\
\text { el-Qurna }\end{array}$ & $\begin{array}{l}\text { Tutmosis IV - } \\
\text { Amenhotep III }\end{array}$ & $\begin{array}{c}\text { Sala transversal, } \\
\text { pared focal }\end{array}$ & $\begin{array}{c}\text { Shedid y Seidel (1996), } \\
\text { Laboury (1997), Davies (1917) } \\
\text { y Maspero (1894) }\end{array}$ \\
\hline 175 & El-Khôkha & $\begin{array}{l}\text { Tutmosis IV - } \\
\text { Amenhotep III }\end{array}$ & $\begin{array}{c}\text { Capilla } \\
\text { longitudinal }\end{array}$ & Manniche (1988b) \\
\hline 249 & $\begin{array}{l}\text { Sheik Abd } \\
\text { el-Qurna }\end{array}$ & Amenhotep III & $\begin{array}{l}\text { Sala transversal, } \\
\text { pared focal }\end{array}$ & Manniche (1988b) \\
\hline TUR & - & Amenhotep III & - & Manniche (1988) \\
\hline 254 & El-Khôkha & Amarna - Ay & $\begin{array}{l}\text { Sala transversal, } \\
\text { pared focal }\end{array}$ & Strudwick (1996) \\
\hline 49 & El-Khôkha & Ay - Horemheb ? & $\begin{array}{l}\text { Dos escenas. } \\
\text { Sala longitudinal, } \\
\text { pared focal }\end{array}$ & Davies (1933) \\
\hline C5 & $\begin{array}{l}\text { Sheik Abd } \\
\text { el-Qurna }\end{array}$ & - & Sala transversal & Manniche (1988) \\
\hline $\mathrm{BM}$ & - & - & - & - \\
\hline BAN & - & - & - & Manniche (1988) \\
\hline DUE & - & - & - & $\begin{array}{c}\text { Manniche (1991) y Duemichen } \\
\text { (1869) }\end{array}$ \\
\hline
\end{tabular}

Fuente: elaboración propia.

El análisis exhaustivo del conjunto de escenas nos permite extraer varias conclusiones.

En primer lugar, se trata de una danza ejecutada siempre por mujeres adultas o niñas. En relación con esto, cabe mencionar que la danza en el antiguo Egipto es una actividad segregada por sexos, es decir, no existen representaciones de hombres y mujeres bailando juntos, sino que puede ser algo realizado por un solo individuo o un grupo, pero siempre personas del mismo sexo.

Las bailarinas parecen moverse en un espacio reducido, a veces sólo entre la orquesta de la que forman parte (como, por ejemplo, en las imágenes encontradas en las TT79, TT129, TT22, TT367, TT75, TT8, TT78, TT52, TT175 y TT249) y en ocasiones parece haber un toque de aire primitivo en su baile (como en las bailarinas de la TT367 o en el fragmento del Museo de Turín). Además, en algunas de estas escenas, como en una de las encontradas en la TT22, es una extranjera, probablemente una nubia, la bailarina solista, lo que le da cierto exotismo a la ocasión. También cabe destacar que, en ocasiones, como en las escenas encontradas en las TT367 o TT38, 
las bailarinas son pintadas con un color de piel más oscuro que el resto de las componentes de la orquesta, lo que también pueda deberse a su origen. El dinamismo de las bailarinas se transmite también a las componentes de las orquestas, quienes hacen movimientos rítmicos dando golpes con sus pies y doblando la rodilla, lo que puede significar que también ellas bailaban (Anderson, 1995).

Así, estas bailarinas en ocasiones también tocan algún tipo de instrumento (generalmente el laúd en el caso de las adultas y unos bastones que se entrechocaban, denominados a veces "castañuelas", en el caso de las niñas), pues siempre son representadas junto a orquestas femeninas formadas por varias mujeres que tocan, entre otros instrumentos, el laúd, la doble flauta u oboe, la pandereta, el arpa o la lira, o que simplemente acompañan rítmicamente la música con sus palmas. Pero éste no es el único acompañamiento musical encontrado en este tipo de escenas, sino que a veces, dentro de la misma escena, existen otros músicos masculinos, sobre todo arpistas, aunque es muy raro encontrarlos en los mismos registros.

Probablemente, que las ejecutoras de estas danzas sean siempre mujeres o niñas se relacione con el carácter simbólico de estas celebraciones o banquetes, en las que era muy importante el componente sensual y erótico, así como la fertilidad, pues ya se ha comentado que estas festividades están relacionadas con la idea de renacimiento del difunto. Quizás, además, sea un reflejo de la realidad de la sociedad de la época y no sólo una convención artística, pues es posible que esta profesión fuera mayoritariamente ejercida por mujeres.

La vestimenta de las instrumentistas se repite: una túnica semitransparente de color blanco que puede ser plisada y amplia o ir ceñida al cuerpo en función de la época en la que fueron realizadas las pinturas, pues estas escenas son también reflejo de las modas de la sociedad del momento.

También se repite el uso de pelucas por parte tanto de las instrumentistas como de las bailarinas. Suele tratarse de pelucas lisas y pelo largo, generalmente hasta el pecho. Algunas, como una de las bailarinas encontradas en la TT129 o la TT78, las del registro superior de la TT22, las encontradas en la TT8, la TT38 y la TT52 o el fragmento del British Museum, incluso han sido representadas claramente con el pelo trenzado.

En relación con esto cabe destacar que en las escenas encontradas en la TT129 y la TT78 (Figura 5), la postura de las bailarinas difiere de la ya descrita y ésta se encuentra en una postura agachada con la espalda curvada hacia delante y el pelo cayendo sobre su cara, tapándosela a la vez que la bailarina intenta ocultarla con sus manos, lo que puede interpretarse como una señal de duelo y relacionarse con el gesto similar de las plañideras que aparecen frecuentemente en los cortejos fúnebres (Valdesogo, 2005).

Además, como se ha mencionado anteriormente, muchas bailarinas e instrumentistas van adornadas con un tocado con una flor de loto y con conos de cera perfumados, ambos elementos cargados de gran simbolismo.

La flor de loto está asociada con el concepto de amor y es considerada como un símbolo de vida eterna y resurrección, pues se cierra por la noche y se abre al amanecer y se pensaba que el dios del sol había nacido de una, ocupando por lo tanto un papel muy importante en las escenas de banquete. Además, se pensaba que su aroma tenía un efecto sedativo o hipnótico que influía en el comportamiento de los dioses y facilitaba la comunicación con ellos, algo buscado en la ya mencionada "Bella Fiesta del Valle". Por otra parte, su esencia o aceite, que se usaba como perfume, se relacionaba con el sudor de los dioses (Green, 2001).

Sin embargo, existe la teoría de que la flor de loto (Nelumbo nucifera), de color rosa, no era conocida por los egipcios del Reino Nuevo, sino que fue introducida desde la India en el periodo persa (siglo VI a.C.). Lo que sí conocían los egipcios eran dos tipos de lirios: el lirio azul (Nymphaea caerulea Savigny) y el blanco (Nymphaea lotus Linnaeus Willdenow). Es por ello posible que las referencias a la "flor de loto" sean incorrectas y en realidad estemos hablando de lirios (Harrington, 2012). Además, existen diferencias notables entre ambos tipos de lirios: mientras que el azul se abre sólo unas horas por la mañana, el blanco lo hace de noche, y la forma de sus pétalos es distinta 
(Wilkinson, 1998).

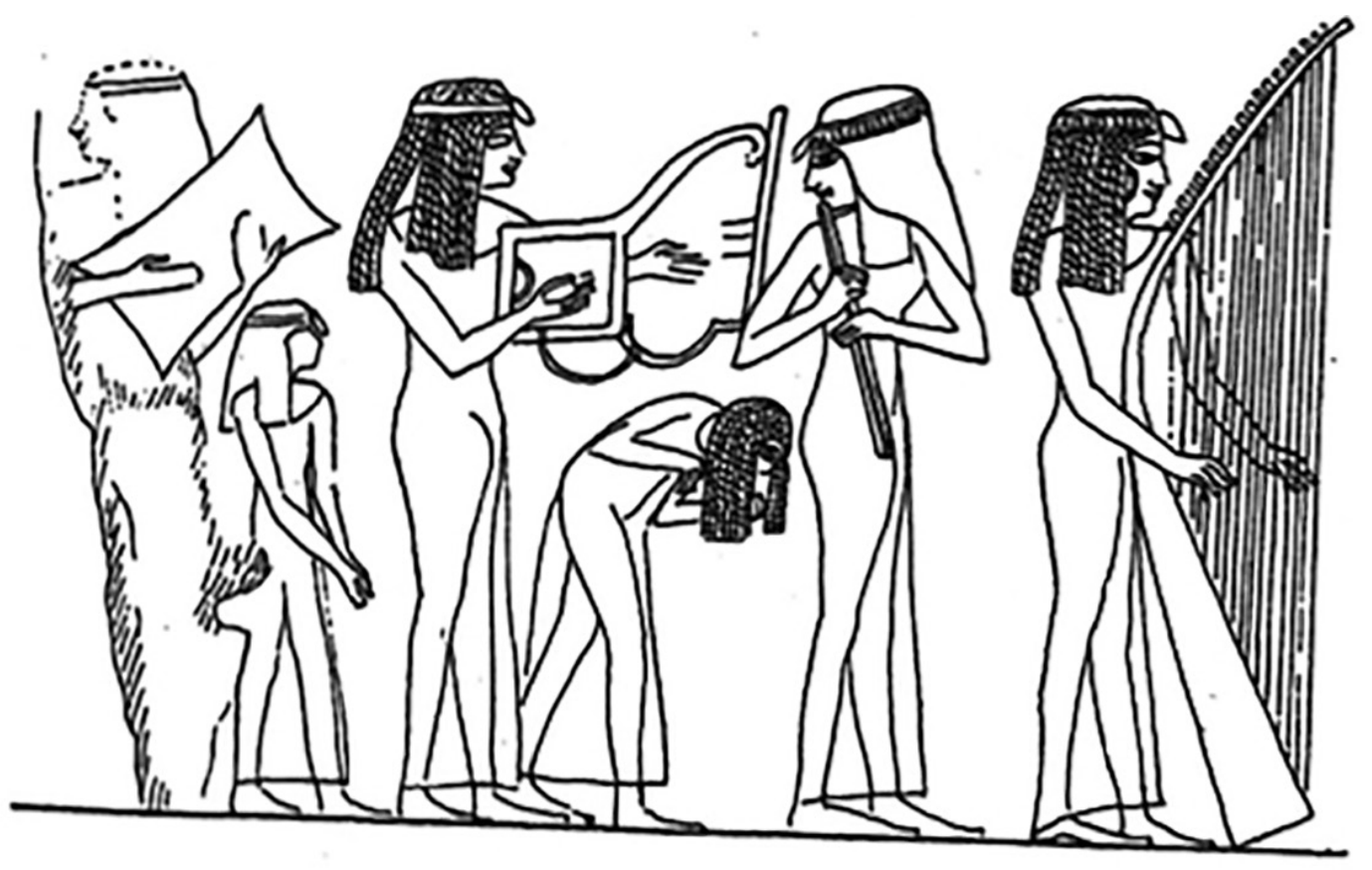

Figura 5: Orquesta y bailarina de la TT129. Fuente: Vandier, 1964, fig. 247, 1.

Por otra parte, existe un debate sobre si los lotos (o lirios) del Nilo tenían o no propiedades narcóticas (Emboden, 1978, 1981; Harer, 1984, 1985). Su naturaleza tóxica es mencionada en textos médicos como el papiro Ebers, pero en este texto no se establece una diferencia entre el lirio azul y el blanco. Diferentes análisis han demostrado la existencia de alcaloides con propiedades psicoactivas en ciertas partes de estas plantas que son solubles en alcohol y no en agua. Es por ello que estas flores, como ya se mencionado, eran añadidas al vino o a la cerveza para activar su poder narcótico. Sin embargo, otros estudios niegan estas capacidades en los lirios (Counsell, 2008). Además, la representación en muchas ocasiones de los lirios azules junto a la mandrágora podría señalar su uso como símbolos eróticos (Szpakowska, 2003).

Los conos de ungüento o cera, situados en la cabeza sobre las pelucas, también son una representación común en las escenas de banquete. Se trata de un símbolo creado a principios de la XVIII dinastía para este tipo de escenas, por lo que nos sugiere que es muy característico de éstas en oposición a las escenas de banquete encontradas en épocas anteriores o que servía para reflejar un aspecto del banquete determinado que no era representado anteriormente (Padgham, 2012). Pero también es posible que estos conos fueran la forma que tenía el artista de representar el aceite de los cabellos y el cuerpo de los personajes y que no fueran reales, sino una manera de representar algo que sólo era posible percibir a través del brillo de las superficies donde estaban impregnados o por su olor (Cherpion, 1994; Manniche, 1999; Padgham, 2012). Sea como fuere, se trata de algo relacionado con el aroma, su efecto en los asistentes al banquete y con ciertas connotaciones sexuales. Además, implican un juego de palabras, pues "aroma" se decía "sti", siendo sus consonantes, de nuevo, las mismas que las de la palabra que describía el acto sexual (Manniche, 1997). En relación con esto, sabemos por diferentes escritos literarios que el olor tenía una gran importancia en la imaginación erótica de los egipcios y éste se vinculaba también con las divinidades y el contacto con ellas. Los conos, a través de su olor, creaban una "atmósfera sagrada" y estaban relacionados con la pureza ritual, además de representar una asociación del difunto con lo divino (Harrington, 2012). Sin embargo, cabe señalar que su frecuencia de aparición también depende del tipo de banquete representado, siendo ésta más frecuente en las representaciones relacionadas con la "Bella Fiesta del Valle", lo que implica que el cono de ungüento y su simbolismo 
están especialmente relacionados con esta festividad, con el culto a los ancestros, que aumenta durante la XVIII dinastía, y con el acceso a la divinidad solar Amón-Ra, así como con la presencia del ba o "alma" del difunto y de los asistentes, facilitando la comunicación entre ellos (Padgham, 2012).

Cabe añadir que algunas bailarinas complementan su vestuario con distintos adornos como cinturones de cuentas, brazaletes, collares, pendientes... lo que se puede interpretar también como un reflejo del momento de esplendor y auge económico que se está viviendo en Egipto en esta época.

En cuanto a las niñas bailarinas, éstas suelen ir desnudas (como símbolo de la pureza e inocencia atribuida a los niños por los egipcios), aunque también pueden aparecer representadas con túnicas, y siempre se encuentran entre las instrumentistas, algo frecuente en las representaciones de niños en el antiguo Egipto, que suelen representarse entre figuras adultas (Seco, 1997). En ocasiones las tocadoras de laúd, que son las adultas que suelen aparecer bailando, también aparecen desnudas, vestidas simplemente con unos pocos adornos (Robins, 1996).

En cuanto a la ubicación de las escenas (Tabla 2), la inmensa mayoría de ellas se encuentran en la sala transversal (recordemos que ésta era considerada el "espacio público" de la tumba) y, dentro de ella, destaca la ubicación de trece de ellas en las llamadas "paredes focales", donde, además de centrarse la atención de los visitantes, es donde se recibía una mayor cantidad de luz solar, por lo que permitía una mejor técnica pictórica. Así los propietarios de las tumbas se aseguraban una representación llamativa que captara la atención de los que entraban en ellas.

\section{Tabla 2}

Número de escenas de danza en banquetes según su ubicación dentro de las tumbas

\begin{tabular}{cc}
\hline Ubicación & $\mathrm{N} .^{\circ}$ de escenas \\
\hline Sala transversal (total) & 22 \\
Sala transversal, paredes focales & 13 \\
Sala transversal, otras paredes & 8 \\
Sala longitudinal & 4 \\
Capilla longitudinal & 2 \\
Desconocida & 4 \\
\hline
\end{tabular}

Fuente: elaboración propia.

Sin embargo, no existe un patrón en cuanto a la orientación de la escena, aunque la de los invitados en las escenas de banquete suela ser contraria al lado donde se encuentra la entrada de la tumba. Tampoco encontramos un patrón en cuanto a la ubicación de las orquestas dentro de las escenas de banquete, pudiendo encontrarse a diferentes alturas en distintos registros, lo que quizás se deba a la necesidad que tenía el artista de adaptarse al espacio disponible.

Pero, aunque la orientación de la escena o de los participantes no sea siempre la misma, algo que se repite en varias de estas representaciones de orquestas femeninas es que las instrumentistas y bailarinas giran su cabeza hacia el lado opuesto al que se orienta su cuerpo, aumentando así la sensación de dinamismo de sus figuras en contraste con el resto de personajes representados.

También cabe destacar que, en cuanto a las propias bailarinas, hay posturas y composiciones repetidas en distintas tumbas, pudiendo ser, como ya se ha dicho, fruto de la copia con ocasión de las visitas a éstas o de la existencia de libros o manuales de modelos.

En cuanto a la composición de las figuras que forman la orquesta, destacan los parecidos entre la TT82, la TT342, la TT100 y la reproducción hecha por Duemichen, en las que las instrumentistas están muy separadas entre sí, probablemente por sus posturas y los instrumentos que tocan (las palmas o la doble flauta u oboe, que es representado alejado del cuerpo y no superpuesto como en otras representaciones posteriores), que no permitiría que fueran representadas más cerca las unas de las otras. Cabe destacar también que las tres primeras tumbas mencionadas tienen, al 
menos, una fase de construcción que coincide con el reinado de Tutmosis III (la copia realizada por Duemichen no está datada de ningún reinado concreto de la XVIII dinastía). Por ello, quizás sea esta representación una convención del momento o quizás unas escenas se inspiren en las otras o estén todas hechas por el mismo artista o escuela.

Por otro lado, y también relativo a su composición, es importante el parecido entre las escenas encontradas en la TT52 y la TT175, en las que las figuras están muy juntas con algunas partes de sus cuerpos incluso superpuestas. En ambas orquestas aparecen las mismas instrumentistas, un trío compuesto por una arpista, una laudista (que es la que baila) y una tocadora de doble flauta u oboe (en este caso, representado delante del pecho de la mujer), y sus posturas, estáticas las dos laterales y con la postura típica de la danza y la cabeza girada la figura central, son las mismas, aunque la escena se encuentra orientada hacia el lado contrario. Ambas tumbas comparten, al igual que las anteriores, su cronología, pues están datadas de los reinados de Tutmosis IV y Amenhotep III. Sin embargo, en esta ocasión se encuentran en necrópolis distintas, estando la TT52 en Sheik Abd el-Qurna y la TT175 en El-Khôkha.

También por su composición son parecidas las orquestas encontradas en la TT129, la TT367, la TT75, la TT38 y el fragmento conservado en la colección Bankes. Se trata, en este caso, de orquestas más numerosas que las anteriores, formadas por seis o más figuras.

Por último, cabe mencionar el parecido de las niñas bailarinas y de la orquesta encontradas en la TT38 y en el fragmento conservado en el Museo de Turín. En ambas escenas (aunque la de Turín se encuentra bastante deteriorada) podemos ver a una laudista bailando con la cabeza inclinada hacia arriba, tocada con una banda blanca y azul; detrás de ella vemos a una niña bailando, con las piernas y los brazos flexionados, y mirando a su compañera con la cabeza también inclinada hacia arriba. Sin embargo, la bailarina del fragmento de Turín tiene uno de sus brazos en alto, mientras que la de la TT38 lo tiene a la altura del pecho. Su peinado y tocado también es diferente, pero es posible que ambas escenas estén relacionadas, tanto por su parecido como por el hecho de que ambas puedan datar del reinado de Amenhotep III.

Es destacable también que, como ya se ha dicho, la mayoría de estas escenas de banquete tienen relación con la "Bella Fiesta del Valle", encontrando incluso alusiones a ella en algunas de las inscripciones, que mencionan la propia fiesta, los cánticos realizados en ella e incluso los nombres de las bailarinas, pero en ningún caso se han encontrado textos explicativos de la danza que realizan.

Por otro lado, también hay ejemplos, como el de la TT82, la tumba de Amenemhat, de banquetes celebrados durante el Festival de Año Nuevo, relacionado también con el renacimiento, o de banquetes más relacionados con el mundo funerario que con el festival, como el de la tumba inacabada de Suenmut, la TT92.

Si hablamos de la ubicación de las tumbas, la mayoría de ellas (diecinueve de los treinta y dos ejemplos) se encuentran en la necrópolis de Sheik Abd el-Qurna (Tabla 3), que como se ha mencionado anteriormente es la sección central de la necrópolis tebana privada y la que concentra mayor número de tumbas de la XVIII dinastía.

Tabla 3

Número de escenas de danza en banquetes según la ubicación de la tumba en la necrópolis tebana

\begin{tabular}{cc}
\hline Ubicación & N. ${ }^{\circ}$ de escenas \\
\hline Sheik Abd el-Qurna & 19 \\
El- Khôkha & 5 \\
Desconocida & 4 \\
Dra Abu el-Naga & 2 \\
El-Asasif & 1 \\
Deir el-Medina & 1 \\
\hline
\end{tabular}

Fuente: elaboración propia. 
Si nos centramos en su cronología, aproximadamente la mitad de ellas coinciden, al menos en algún momento de la construcción de la tumba, con el reinado de Tutmosis III (TT251, TT53, TT18, TT82, TT342, TT79, TT80, TT92, TT100, TT192, TTA5, TT22), un periodo de esplendor y estabilidad en Egipto, y casi todas ellas pertenecen al periodo pre-amarniense (Tablas 1 y 4 ).

Tabla 4

Número de escenas de danza en banquetes según su datación

\begin{tabular}{ccc}
\hline Época & $\mathrm{N}^{\circ}{ }^{\circ}$ de escenas & Tumbas \\
\hline $\begin{array}{c}\text { Pre-amarniense } \\
\begin{array}{c}\text { Amarniense o } \\
\text { inmediatamente } \\
\text { posterior }\end{array}\end{array}$ & 23 & $\begin{array}{c}\text { TT251, TT53, TT18, TT82, TT342, TT79, TT80, TT92, } \\
\text { TTA5, TT22, TT367, TT75, TT176, TT8, TT78, TT297, } \\
\text { TT38, TT52, TT175, TT249 y fragmento del Museo de } \\
\text { Turín }\end{array}$ \\
$\begin{array}{c}\text { Desconocida } \\
\text { Fuente: }\end{array}$ & 3 & $\begin{array}{c}\text { TT254 y TT49 } \\
\text { TTC5, fragmentos del Museo Británico y la Colección } \\
\text { Bankes y copia realizada por Duemichen }\end{array}$ \\
\hline
\end{tabular}

Fuente: elaboración propia.

Por otra parte, a lo largo de esta investigación no se ha podido atestiguar que exista una relación entre las profesiones de los propietarios de las tumbas y este tipo de representaciones, por lo que se puede decir que forman parte del repertorio iconográfico de las tumbas no por el cargo del difunto o sus títulos principales, sino por ser escenas llamativas que eran adecuadas para incluirse en sus monumentos, por preferencias personales o quizás por otro tipo de relación menos obvia entre ellos.

Por último, cabe mencionar que se han encontrado otras orquestas femeninas con bailarinas representadas en las tumbas tebanas privadas de la XVIII dinastía (TT179, TT109 y TT90), pero que, debido bien a la falta de la escena completa y, por lo tanto, del contexto, o bien a importantes diferencias iconográficas con las escenas analizadas no se han incluido en este estudio por no encontrar evidencias o interpretaciones claras que permitan agruparlas con las incluidas.

\section{Reflexiones finales}

Tras el análisis realizado podemos extraer varias conclusiones destacadas para la comprensión de la importancia y significado de estas escenas de danza.

Las primeras son relativas a su contexto y cronología. La mayor parte se encuentran en tumbas privadas de Sheik Abd el-Qurna, lo cual puede deberse simplemente a la tendencia que existía en ese momento entre la elite tebana de construir su tumba en esta parte de la necrópolis. Además, la mayor parte de las representaciones están datadas de la primera mitad de la XVIII dinastía, el periodo anterior a la ruptura de Amarna, lo que puede ser indicativo del periodo de prosperidad y estabilidad que vive Egipto en este momento y que se ve alterado por los cambios sufridos durante el reinado de Akenatón. Por otra parte, podemos asegurar que muchas de estas escenas están relacionadas con distintos festivales, destacando entre ellos la "Bella Fiesta del Valle" (Padgham, 2012).

Dentro de las tumbas las imágenes de danza dentro de banquetes se encuentran en su mayoría en la sala transversal, y dentro de ésta en las "paredes focales", lo que revela que se trata de una tipología de escena importante en el repertorio decorativo de las tumbas, que debía estar formado por imágenes llamativas y atractivas para el potencial visitante y que tuvieran un importante simbolismo (Hartwig, 2014). 
La danza es siempre ejecutada por personajes femeninos, mujeres o niñas, que forman parte de orquestas con varias instrumentistas, lo que hace pensar que existía cierta especialización de las bailarinas. Su postura es casi siempre la misma, las piernas flexionadas y un talón levantado del suelo, aunque se han encontrado variaciones e incluso posturas diferentes a la descrita. Aunque existen detalles concretos de las poses copiados de una tumba a otra, no se han documentado dos escenas de danza idénticas, lo que revela la originalidad y personalidad de cada artista o cuadrilla de artistas que trabajaba en una tumba.

En cuanto a su función, podemos intuir, gracias a distintos elementos relacionados con las bailarinas, que tenían un significado simbólico relacionado con el erotismo y la sexualidad, y a través de ellos, con la necesidad de renacimiento del difunto, de la vuelta a la vida después de la muerte, algo de gran importancia en la religión egipcia (Kroeter, 2009).

En definitiva, las escenas de danza en banquetes de la XVIII dinastía documentadas en la necrópolis tebana se conforman como una serie de imágenes cargadas de contenido simbólico, que resultarían llamativas para aquel que visitase la tumba. La imagen de las bailarinas danzando en las escenas de banquete podría funcionar como un símbolo llamativo y claro que servía de nexo entre el difunto y los sacerdotes, amigos o familiares que perpetuaban su memoria. Perdurar en el tiempo, en la sociedad y en la memoria colectiva era en cierto modo para los antiguos egipcios vencer a la muerte.

\section{Bibliografía}

Aldred, C. (1951). New Kingdom art in ancient Egypt during the eighteenth dynasty. Londres: A. Tiranti.

Anderson, R. D. (1995). Music and Dance in Pharaonic Egypt. En J. M. Sasson, Civilizations of the Ancient near East, vol. VI (pp. 2555-2568). Nueva York: Scribner's.

Bleiberg, E. (2005) Dance. En E. Bleiberg (ed.), Arts and Humanities through the Eras. Ancient Egypt 2657-332 B.C.E. (pp. 64-85). Detroit: Thomson Gale.

Bolshakov, A. O. (1991). The Moment of the Establishment of the Tomb-Cult in Ancient Egypt. Altorientalische Forschungen, 18, 204-218.

Bosse-Griffiths, K. (1983). The Fruit of the Mandrake. En M. Görg (ed.), Fontes Atque Pontes, 5 (pp. 62-74). Wiesbaden: Harrasowitz.

Bouriant, U. (1889). Tombeau De Harmhabi. Mémoires publiés par les membres de la mission archéologie française au Caire, 5(2), 413-434.

Brack, A. y Brack, A. (1980). Das Grab des Haremheb: Theben Nr. 78. Mainz am Rein: Philipp von Zabern.

Brunner-Traut, E. (1958). Der Tanz im Alten Ägypten. Nach bildlichen und inschriftlichen Zeugnissen. Glückstadt, Hamburgo, Nueva York: J. J. Augustin.

Bryan, B. M. (2001). Painting techniques and artisan organization in the Tomb of Suemniwet, Theban Tomb 92. En W. V. Davies (ed.), Colour and Painting in Ancient Egypt (pp. 63-72). Londres: British Museum Press.

Bryan, B. M. (2009). Memory and knowledge in Egyptian tomb painting. En E. Cropper (ed.), Dialogues in Art History, from Mesopotamian to Modern: Readings for a new century (pp. 1939). Washington: National Gallery of Art.

Bryan, B. M. (2010). La XVIII Dinastía antes del Período Amárnico (c. 1550-1352 a.C.). En I. Shaw, Historia del antiguo Egipto (pp. 287-357). Madrid: La esfera de los libros.

Bryan, B. M. (2015). "Just Say 'No'"-Iconography, Context, and Meaning of a Gesture. En A. Oppenheim y O. Goelet (eds.), The Art and Culture of Ancient Egypt: Studies in Honor of Dorothea Arnold, Bulletin of the Egyptological Seminar (BES) (vol. 19) (pp. 187-198). Nueva York: Egyptological Seminar of New York.

Calcoen, B. (2012). TT176: The Tomb Chapel of Userhat. Londres: Golden House Publications.

Counsell, D. J. (2008). Intoxicants in Ancient Egypt? Opium, nymphea, coca, and tobacco. En R. 
David (ed.), Egyptian mummies and modern science (pp. 195-215). Cambridge: Cambridge University Press.

Cherpion, N. (1994). Le "cône" d'onguent, gage de survie. Bulletin de l'Institut Français d'Archéologie Orientale (BIFAO), 94, 79-106.

Daumas, F. (1977). Hathor, Lexikon der Ägyptologie (LÄ), II, col. 1024-1033.

Davies, N. de G. (1963). Scenes from Some Theban Tombs (Nos. 38, 66, 162, with Excerpts from 81). Oxford: Griffith Institute.

Davies, N. de G. y Gardiner, A. H. (1915). The tomb of Amenemhet (no. 82). Oxford: Oxford University Press.

Davies, N. de G. (1917). The tomb of Nakht at Thebes. Nueva York: Metropolitan Museum of Art.

Davies, N. de G. (1933). The tomb of Nefer-hotep at Thebes. Nueva York: Metropolitan Museum of Art.

Davies, N. de G. (1935). Paintings from the Tomb of Rekh-mi-Re'at Thebes. Nueva York: Metropolitan Museum of Art.

Davies, N. de G. (1943). The Tomb of Rekh-mi-Re' at Thebes. Nueva York: Metropolitan Museum of Art.

Davies, N. de G. (1923). The Tombs of Two Officials of Tuthmosis the Fourth (nos. 75 and 90). Londres: Egypt Exploration Society.

Den Doncker, A. (2017). Identifying-Copies in the Private Theban Necropolis. Tradition as Reception under the Influence of Self-Fashioning Processes. En T. Gillen (ed.), (Re)productive Traditions in Ancient Egypt, Universidad de Lieja, 6-8 de Febrero de 2013 (pp. 333-370). Lieja: Presses Universitaires de Liège.

Dodson, A. e Ikram, S. (2008). The tomb in Ancient Egypt: royal and private sepulchres from the early dynastic period to the Romans. Londres: Thames \& Hudson.

Drioton, E. (1948). La danse dans l'ancienne Égypte. La Femme Nouvelle, 24-32.

Duemichen, J. (1869). Historische Inschriften Altägyptischer Denkmäler. Leipzig: J. C. Hinrichs.

Emboden, W. A. (1978). The sacred narcotic lily of the Nile: Nymphaea caerulea. Economic Botany, $32,395-407$.

Emboden, W. A. (1981). Transcultural use of narcotic water lilies in ancient Egyptian and Maya drug ritual. Journal of Ethnopharmacology, 3, 39-83.

Fakhry, A. (1943). Tomb of Paser ( $\mathrm{n}^{\circ} 367$ at Thebes). Annales du service des antiquités de l'Égypte, 43, 389-414.

Foucart, G. (1924). La Belle Fête de la Vallée. Bulletin de I'Institut Français d'Archéologie Orientale, 24, 1-209.

Gauthier, H. (1908). Rapport sur une campagne de fouilles à Drah Abou'l Neggah en 1906. Bulletin de l'Institut Français d'Archéologie Orientale, 6, 163-171.

Graves-Brown, C. (2010). Dancing for Hathor: women in ancient Egypt. Londres: Bloomsbury Publishing.

Green, L. (2001). Toiletries and cosmetics. En D. B. Redford (ed.), The Oxford Encyclopedia of Ancient Egypt, vol. 3. Oxford: Oxford University Press.

Guksch, H. (1995). Die Gräber des Nacht-Min und des Men-cheper-Ra-seneb, Theben Nr. 87 und 79. Mainz: Philipp von Zabern.

Harer, W. B. (1984). Nymphaea: Sacred Narcotic Lotus of Ancient Egypt? Journal of the Society for the Study of Egyptian Antiquities, 14, 100-102.

Harer, W. B. (1985). Pharmacological and biological properties of the Egyptian lotus. Journal of the American Research Center in Egypt (JARCE), 22, 49-54.

Hartwig, M. K. (2004). Tomb painting and identity in ancient Thebes, 1419-1372 BCE. Turnhout: Brepols.

Harrington, N. (2012). Living with the dead: Ancestor worship and mortuary ritual in Ancient Egypt. Oxford: Oxbow Books.

Harrington, N. (2014). The Eighteenth Dynasty Egyptian banquet: ideals and realities. En Draycott, 
C. (ed.), Dining and death. Interdisciplinary perspectives on the "funerary banquet" in ancient art, burial and belief. Leuven: Peeters.

Ikram, S. (2001). Banquets. En D. B. Redford (ed.), The Oxford Encyclopedia of Ancient Egypt (vol. 1). Oxford: Oxford University Press.

Jiménez, Á. (2016). Development and Landscape of the Sacred Space at Dra Abu el-Naga: A case study within the Theban Necropolis (Tesis doctoral inédita). University of Liverpool.

Kampp-Seyfried, F. (2003). The Theban necropolis: an overview of topography and tomb development from the Middle Kingdom to the Ramesside period. En N. Strudwick y J. H. Taylor (eds.), The Theban Necropolis: past, present and future (pp. 2-10). Londres: The British Museum Press.

Kroeter, C. (2009). The sensual banquet scene: sex and senses in Eighteenth Dynasty Theban Tomb Paintings. North Street Review: Arts and visual culture, 13, 47-56.

Laboury, D. (1997). Une relecture de la tombe de Nakht (TT52, Cheikh Abd el-Gourna). En R. Tefnin (ed.), La Peinture Égyptienne Ancienne: Un monde de signes à préserver, Actes de colloque international de Bruxelles (pp. 49-81). Bruselas: Fondation Égyptologique Reine Élisabeth.

Laboury, D. (2017). Tradition and Creativity. Toward a Study of Intericonicity in Ancient Egyptian Art. En T. Gillen (ed.), (Re)productive Traditions in Ancient Egypt (pp. 229-258). Lieja: Presses Universitaires de Liège.

Lexová, I. (1935). Ancient Egyptian Dances. Praga: Instituto Oriental.

Manniche, L. (1987). City of the Dead: Thebes in Egypt. Londres: British Museum Publications.

Manniche, L. (1988). Lost Tombs: A Study of Certain Eighteenth Dynasty Monuments in the Theban Necropolis. Londres: KPI.

Manniche, L. (1988b). The Wall Decoration of Three Theban Tombs (TT 77, 175, and 249). Copenhage: Museum Tusculanum Press.

Manniche, L. (1991). Music and Musicians in Ancient Egypt. Londres: British Museum Press.

Manniche, L. (1997). El arte egipcio. Madrid: Alianza Forma.

Manniche, L. (1997b). Reflections on the banquet scene. En R. Tefnin (ed.), La Peinture Égyptienne Ancienne: Un monde de signes à préserver, Actes de colloque international de Bruxelles (pp. 29-36). Bruselas: Fondation Égyptologique Reine Élisabeth.

Manniche, L. (1999). Sacred Luxuries: Fragrance, Aromatherapy, and Cosmetics in Ancient Egypt. Nueva York: Cornell University Press.

Manniche, L. (2003). The so-called scenes of daily life in the private tombs of the Eighteenth Dynasty: an overview. En N. Strudwick y J. H. Taylor (eds.), The Theban Necropolis: past, present and future (pp. 42-45). Londres: British Museum Publications Limited.

Manzi, L. M. y Pereyra, M. V. (2014). El banquete funerario y la Bella Fiesta del Valle en Tebas occidental. NEARCO. Revista Eletrônica de Antiguidade, 1, 238-259.

Maspero, G. (1894). Tombeau de Nakhti. Mémoires publiés parles membres de la mission archéologie française au Caire, 5, 469-485.

Mekhitarian, A. (1957). Un peintre thébain de la XVIIle dynastie. Mitteilungen des Deutschen Archäologischen Instituts, Abteilung Kairo, 15, 186-192.

Meyer-Dietrich, E. (2009). Dance. En W. Wendrich et alii (eds.), UCLA Encyclopedia of Egyptology. Los Ángeles, CA: University of California.

Morgan, L. (2015). Why is no one eating? The iconography of feasting in the ancient world. Journal of Ancient Egyptian Interconnections, 7(3), 49-64.

Naguib, S. A. (1991). The Beautiful Feast of the Valley. En R. Skarsten, E. J. Kleppe y R. B. Finnestad (eds.), Understanding and History in Arts and Sciences, Acta Humaniora Universitatis Bergensis (pp. 21-32). Oslo: Solum.

Navrátilová, H. (2010). Graffiti spaces. En L. Bareš et alii (eds.), Egypt in transition: social and religious development of Egypt in the first millennium BCE: Proceedings of an International Conference, Praga, 1-4 de Septiembre de 2009 (pp. 305-332). Praga: Czech Institute of Egyptology, Faculty of Arts, Charles University in Prague.

Padgham, J. (2012). A new interpretation of the cone on the head in New Kingdom Egyptian tomb 
scenes. Oxford: Archaeopress.

Pirelli, R. (2007). Les répertoires de scènes des tombeaux privés de la 18ème dynastie et les scènes de banquet: présentation d'une étude. En J.-C. Goyon y C. Cardin (eds.), Proceedings of the Ninth International Congress of Egyptologists: Grenoble, 6-12 septembre 2004 (pp. 15191525). Leuven: Peeters.

Porter, B. y Moss, R. L. B. (1970). Topographical bibliography of ancient Egyptian hieroglyphic texts, reliefs and paintings. Oxford: Griffith Institute, Ashmolean Museum.

Robins, G. (1996). Dress, Undress, and the Representation of Fertility and Potency in New Kingdom Egyptian Art. En N. B. Kampen et alii, Sexuality in ancient art. Near East, Egypt, Greece, and Italy (pp. 27-40). Cambridge: Cambridge University Press.

Schenkel, W. (1975). Die Gräber des $P_{3-\underline{t} n f-j}$ und eines Unbekannten in der Thebanischen Nekropole (Nr. 128 und Nr. 129). Mitteilungen des Deutschen Archäologischen Instituts, Abteilung Kairo, 31, 127-158.

Schiaparelli, E. (2007). La tomba intatta dell'architetto Kha nella necropoli di Tebe. Turín: Adartep.

Schott, S. (1953). Das schöne Fest vom Wüstentale: Festbräuche einer Totenstadt. Wiesbaden: Akademie der Wissenschaften und der Literatur, F. Steiner.

Seco, M. (1997). El niño en las pinturas de las tumbas tebanas de la XVIII dinastía. Sevilla: Kolaios.

Seidel, M. (1996). The Necropolis of Western Thebes to the End of the New Kingdom. En A. G. Shedid y M. Seidel, The tomb of Nakht: The art and history of an eighteenth dynasty official's tomb at Western Thebes (pp. 9-11). Mainz am Rhein: Philipp von Zabern.

Shedid, A. G. (1988). Stil der Grabmalereien in der Zeit Amenophis'll: Untersucht an den Thebanischen Gräbern Nr 104 und 80. Mainz am Rhein: Philipp von Zabern.

Shedid, A. G. y Seidel, M. (1996). The tomb of Nakht: The art and history of an eighteenth dynasty official's tomb at Western Thebes. Mainz am Rhein: Philipp von Zabern.

Smith, W. S. (2009). Arte y arquitectura del antiguo Egipto. Madrid: Cátedra.

Spalinger, A. J. (2001). Festivals. En D. B. Redford (ed.), The Oxford Encyclopedia of Ancient Egypt, vol. 1. Oxford: Oxford University Press.

Strudwick, N. (1996). The Tombs of Amenhotep, Khnummose, and Amenmose at Thebes (Nos. 294, 253, and 254). Oxford: Griffith Institute.

Strudwick, N. (2003). The tomb of Amenemopet called Tjanefer at Thebes (TT 297). Abhandlungen des Deutschen Archäologischen Instituts Kairo. Berlín: Achet.

Szpakowska, K. (2003). Altered states: an inquiry into the possible use of narcotics or alcohol to induce dreams in Pharaonic Egypt. En A. K. Eyma y C. J. Bennett (eds.), A Delta-man in Yebu (pp. 225-237). Florida: Universal-Publishers.

Teeter, E. (2011). Religion and ritual in ancient Egypt. Nueva York: Cambridge University Press.

Van Dijk, J. (2010). El periodo amárnico y el final del Reino Nuevo. En I. Shaw, Historia del antiguo Egipto (pp. 359-410). Madrid: La esfera de los libros.

Vandier, J. (1964). Manuel d'archéologie égyptienne. Tome IV: Bas-reliefs et peintures. Scènes de la vie quotidienne. París: Auguste et J. Picard.

Vandier d'Abbadie, J. (1939). Deux tombes de Deir el-Medineh. Mémoires publiés par les membres de l'Institut français d'archéologie orientale, 73, 1-18.

Vischak, D. (2001). Hathor. En D. B. Redford (ed.), The Oxford Encyclopedia of Ancient Egypt. Oxford: Oxford University Press.

Valdesogo, M. R. (2005). El cabello en el ritual funerario del Antiguo Egipto a partir de los Textos de los Sarcófagos y de la evidencia iconográfica. Barcelona: Aula Aegyptiaca.

Virey, P. (1889). Le Tombeau de Rekhmare, Préfet de Thèbes sous la XVIIle Dynastie. Mémoires publiés par les membres de la mission archéologie française au Caire. París: Ernest Leroux.

Virey, P. (1891). Tombeau de Menkheper. Mémoires publiés par les membres de la mission archéologie française au Caire, 5, 322-336.

Vivas, I. (2014). Identidad religiosa e identidad social: innovaciones en el programa decorativo de las tumbas tebanas privadas de la XVIII Dinastía. En S. Acerbi (ed.), Actas del X Congreso de 
la Sociedad Española de Ciencias de las Religiones (pp. 21-34). Santander: Universidad de Cantabria.

Wild, H. (1963). Les danses sacrées de l'Égypte ancienne. París: Tire a Part.

Wilkinson, A. (1998). The Garden in Ancient Egypt. Londres: Rubicon Press. 



\section{Panta Rei}

PANTA REI es una revista digital de investigación orientada a la Historia y otras ciencias afines. Su principal objetivo es la transmisión del conocimiento científico, dando una oportunidad también a los jóvenes investigadores que quieren abrirse camino en el estudio de las ciencias humanas y sociales. Se compone de estudios originales relacionados con la disciplina histórica así como su didáctica y difusión. Las diferentes secciones que componen la revista son: artículos de investigación, entrevistas a profesionales, recensiones de monografías de actualidad y crónicas de congresos o eventos científicos relevantes.

Todos los artículos publicados son objeto de un proceso de revisión a cargo de un mínimo de dos evaluadores, que se consideran expertos en el ámbito temático del artículo propuesto. Nuestro deseo es poder ofrecer unos contenidos rigurosos, de calidad y de interés.

EI CEPOAT (Centro de Estudios del Próximo Oriente y la Antigüedad Tardía de la Universidad de Murcia) es la institución encargada de la coordinación y gestión de la revista, desde donde anualmente se lanzará la convocatoria para aquellos que estén interesados en publicar sus trabajos, siempre relacionados con la Historia, Arqueología, Historia del Arte, Didáctica de la Historia, etc.

PANTA REI is a digital journal focused on History and other sciences related to it. Its main objective is the transmission of scientific knowledge by giving also an opportunity to young researchers who want to make their way in the study of human and social sciences. It is composed by original studies related to History, as well as its didactics and promotion. The different sections of this journal are: research articles, interviews to professionals, recensions on monographs about current issues and reports about congresses or relevant scientific events.

All the articles published are subject to a revision process carried out by a minimum of two reviewers who are considered to be experts in the field of the article proposed. Our wish is to offer rigorous contents with quality and being of interest to the reader.

CEPOAT (Centre of Studies of the Middle East and Late Antiquity of the University of Murcia) is the institution in charge of the coordination and management of this journal. This is the centre from where the call for papers will be launched for all the people interested in publishing their papers, always related to History, Archeology, Art History, Teaching History, etc. 


\section{Normas de Publicación}

El autor se compromete a enviar trabajos originales, que no se encuentren publicados en otras revistas ni en otros idiomas. Así mismo, el mismo artículo no podrá ser presentado en otras revistas mientras dure el proceso de evaluación.

\section{Envío y presentación de originales}

Los artículos se enviarán exclusivamente a través del correo electrónico a la dirección pantarei@um.es. Los textos serán enviados en formato DOC y las imágenes en formato JPEG o TIFF, y con un tamaño mínimo de 2000 px. Éstas no aparecerán incorporadas en el texto, sino enviadas en archivo aparte y correctamente numeradas según su posición en el texto. Junto al trabajo, se rellenará y enviará un documento aparte en el que se especifiquen los datos del autor siguiendo el modelo disponible en la página Web de la revista.

Para la redacción de los trabajos se tendrá en cuenta el Manual de la American Psychological Association, en su sexta edición. La extensión máxima de los trabajos será de 30 páginas. La tipografía será Arial 11, con interlineado sencillo y sin espacio alguno entre párrafos. El texto deberá ir justificado a ambos márgenes y sin sangría en los primeros párrafos. Los márgenes serán de $2,50 \mathrm{~cm}$. En los casos en los que fuera necesario incorporar notas, éstas irán a pie de página, enumeradas consecutivamente, con tipografía Arial 10, interlineado sencillo y justificadas a ambos márgenes.

Una información más detallada se encuentra disponible en la página http://www.um.es/cepoat/ pantarei.

\section{Proceso de valoración y evaluación}

Una vez recibidos los trabajos, la Revista realizará una primera valoración. Si el trabajo enviado se ajusta a las normas de presentación propuestas, la temática es coincidente con la línea editorial de la revista y posee la calidad científica necesaria, será remitido al consejo asesor para una primera evaluación. Si no es así en este primer paso se puede rechazar directamente los documentos que incumplan claramente la línea editorial.

Será el Consejo Asesor quien indique a la revista la originalidad, relevancia, estructura, redacción, aparato bibliográfico, etc. del trabajo enviado y, para ello, se designará a dos revisores expertos externos que evaluarán cada uno de los trabajos, que pueden formar parte (o no) de este Consejo Asesor. La selección de los revisores se ajustará a la temática y características metodológicas del trabajo. El nombre y filiación de los autores serán eliminados del trabajo para su revisión, así como los revisores actuarán de manera anónima y confidencial.

Los revisores deberán rellenar un informe de evaluación que centrará su atención en aspectos tales como características formales, originalidad y novedad de los trabajos, relevancia de las propuestas y los resultados, calidad metodológica y validez científica.

Una vez terminado el proceso se decidirá la aceptación o no de los mismos y su publicación en el número que sea pertinente, así como las modificaciones susceptibles de ser realizadas para su final publicación. Dicha notificación se enviará únicamente por correo electrónico, en un plazo máximo de seis meses. 


\section{Publishing rules}

The author is committed to submit original papers not having been published in other reviews or in other languages. In this way, it is not allowed for the same paper to be presented in other reviews during the evaluation process.

\section{Submission and presentation of originals}

The articles will be exclusively submitted by email to pantarei@um.es. The texts will be submitted in DOC format and the images in JPEG or TIFF format, and with a minimum size of 2000 px. Images will not be integrated in the text but sent in another file and properly numbered according to their position in the text. Attached to the paper, a document will be filled out and sent where the author's data will be specified following the model available on the website.

The sixth edition of the Manual of the American Psychological Association will be taken into account for the writing of the papers. The length of the papers must not exceed 30 pages. Typography will be Arial 11 , with simple line spacing and no space between paragraphs. The text must be justified on both margins without indentation in the first paragraphs. Margins size will be $2.50 \mathrm{~cm}$. Where it could be necessary the incorporation of notes, they will be at the bottom of the page, consecutively numbered with typography Arial 10, simple line spacing and justified on both margins.

More detailed information is available on the website: http://www.um.es/cepoat/pantarei.

\section{Examination and assessment process}

The Journal will submit the papers to a first examination once received. If the paper follows the presentation guidelines, the subject agrees with the editorial line of this journal, and possess the scientific quality required, it will be sent to the advisory council for a first assessment. If not, the documents which clearly fail to complete the editorial line may be rejected straightaway in this first step.

The Advisory Council will indicate the originality, relevance, structure, writing, bibliography, etc. of the text to the journal; for this purpose, two outside experts will be designated to review the papers; these experts can be (or not) part of this Advisory Council. The selection of the experts will adjust to the subject and methodological characteristics of the paper. Name and affiliation of the author will be eliminated from the text for its review, in this way experts will act anonymously and confidentially.

The experts will fill out an assessment report which will focus on aspects such as formal characteristics, originality and novelty of the papers, relevance and results of the proposal, methodological quality and scientific validity.

Once the process is finished, the acceptance or not of the papers and its publication in the corresponding edition will be decided, as well as the modifications that may be done for its final publication. This notification will be sent by email within 6 months maximum. 


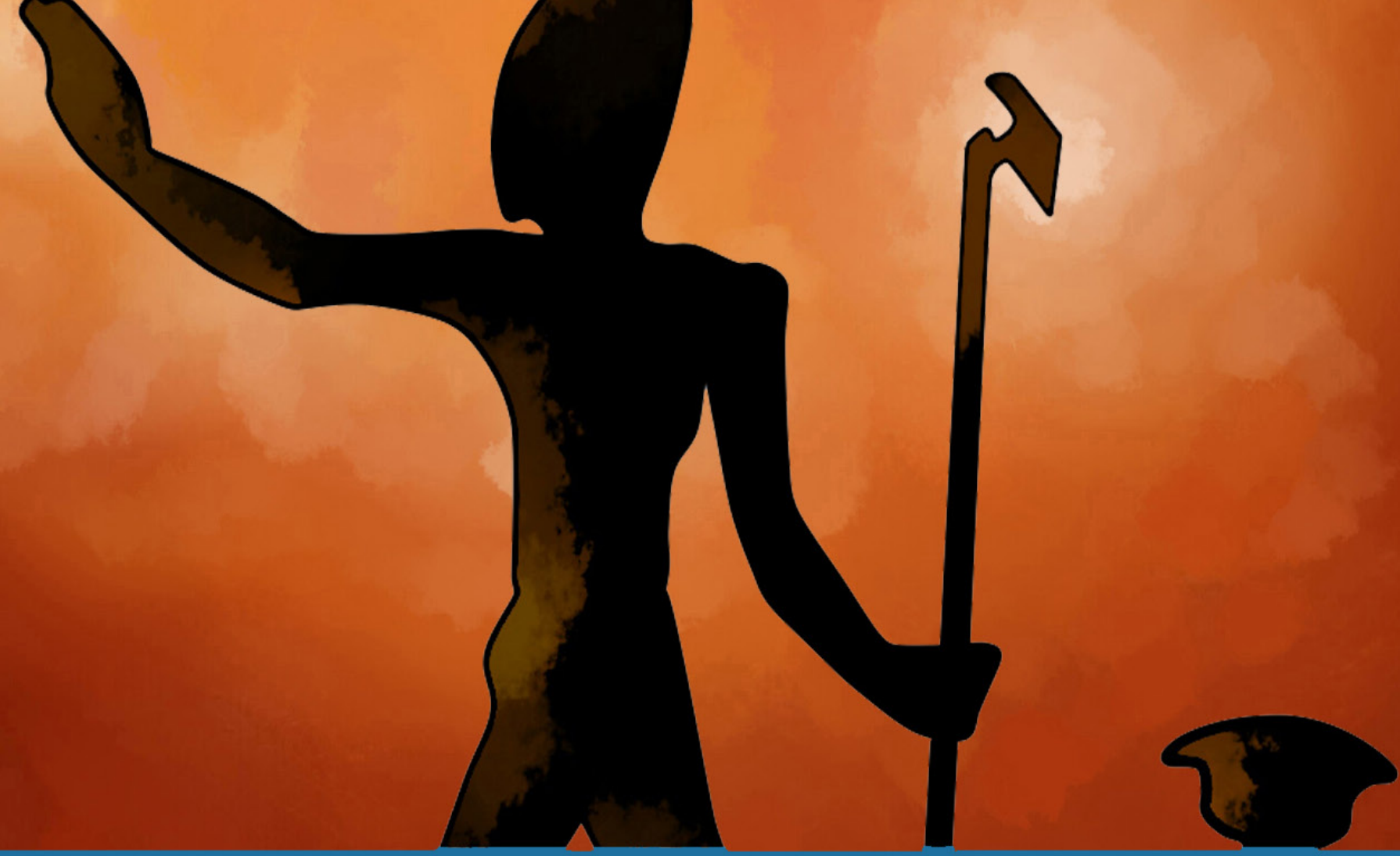

GepOA

centro de estudios de

próximo oriente y la

antigüedad tardía 